\title{
PERFORMANCE ANALYSIS OF REINFORCED HIGH-STRENGTH CONCRETE BEAMS UNDER IMPACT LOADING
}

by

\section{Seyed Masoud Sadri}

B.Eng., Ryerson University 2014

\author{
A thesis \\ presented to Ryerson University \\ in partial fulfillment of the \\ requirements for the degree of \\ Master of Applied Science \\ in the program of \\ Civil Engineering
}

Toronto, Ontario, Canada, 2017

(C) Seyed Masoud Sadri, 2017 


\begin{abstract}
AUTHOR'S DECLARATION
I hereby declare that I am the sole author of this dissertation. This is a true copy of the dissertation, including any required final revisions, as accepted by my examiners.

I authorize Ryerson University to lend this dissertation to other institutions or individuals for the purpose of scholarly research.

I further authorize Ryerson University to reproduce this dissertation by photocopying or by other means, in total or in part, at request of other institutions or individuals for the purpose of scholarly research.

I understand that my dissertation may be made electronically available to the public.
\end{abstract}




\title{
ABSTRACT \\ PERFOMANCE ANALYSIS OF REINFORCED HIGH-STRENGTH CONCRETE BEAMS UNDER IMPACT LOADING
}

\author{
Seyed Masoud Sadri \\ Master of Applied Science, Civil Engineering \\ Ryerson University, Toronto, 2017
}

An experimental investigation is conducted to analyze the performance of reinforced high strength concrete (HSC) beams under impact loading. Six reinforced HSC beams with identical dimensions and varying reinforcement ratios and span length are tested using drop-weight impact setup with a $475 \mathrm{~kg}$ steel weight from a clear height of $4.15 \mathrm{~m}$.

The experimental results have confirmed that beams with a steel reinforcement ratio ranging from $1.2 \%-1.8 \%$ suffer more damage and shear cracks are more visible and wider compared to beam with a steel reinforcement ratio of $0.5 \%$. Beams with a shear span to effective depth ratio $(\mathrm{a} / \mathrm{d})$ of 4.28 sustained more damage and wider shear cracks in comparison to beams with an a/d ratio of 3.21. A static to dynamic load ratio of about 0.5 , and a static to dynamic displacement ratio of about 2 may be utilized for estimating the impact behavior of statically flexure beams. 


\section{ACKNOWLEDGMENTS}

The presented research work in this MSc dissertation was carried out at the department of civil engineering in Ryerson University with supervision of Professor Hesham Marzouk.

I would like to express my special appreciation to my supervisor and thesis advisor, Dr. Hesham Marzouk for all his support and assistance, and his mentorship through the course of my graduate studies. I would also like to appreciate my colleague, Dr. Hesham Othman for his help and assistance with test setup and data analysis. Additionally, I wish to express my appreciation and thanks to the committee members, Dr. Medhat Shehata and Dr. Jinyuan Liu for kindly reviewing my dissertation.

Foremost, I would like to tribute the endless support and love of my family and my dear mother in this memorable process, which would have never been completed without them. Finally, I would like to praise the mighty god, for giving me the strength and power during the course of my life to be the person I am today. 


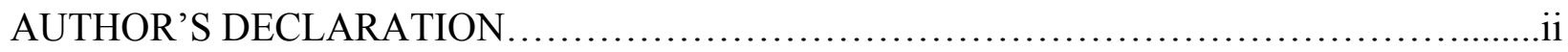

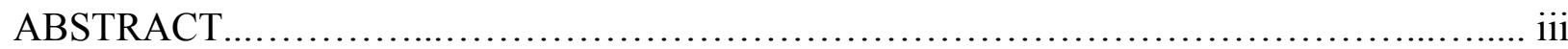

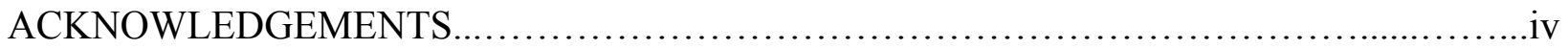

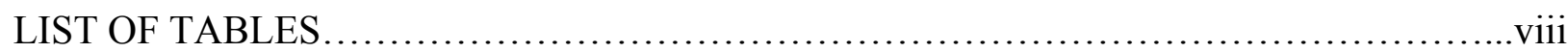

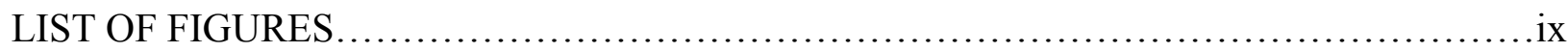

LIST OF ABBREVIATIONS ..........................................................

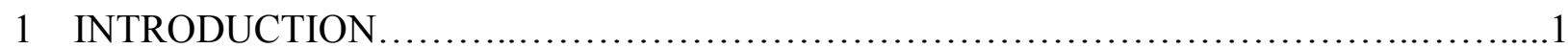

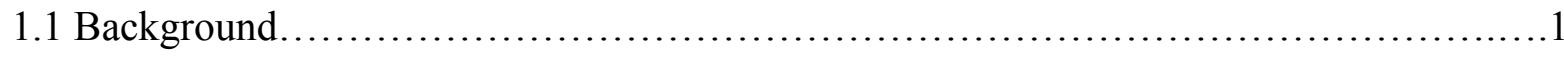

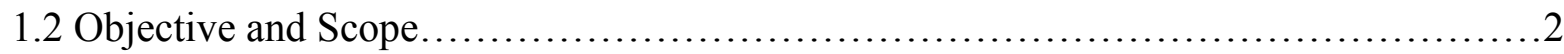

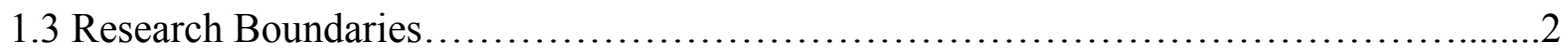

1.4 Outline of the Research Report..............................................

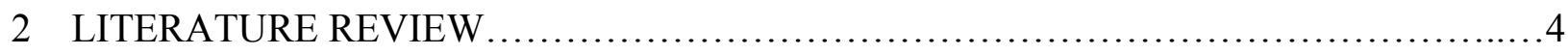

2.1 Background of Concrete Beams.............................................4

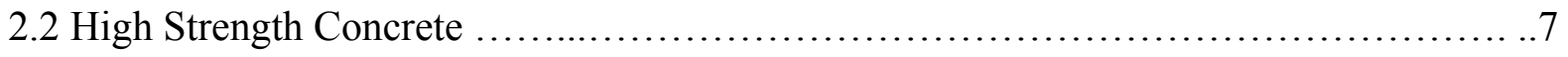

2.2.1 Tension Properties of High Strength Concrete..................................... 8

2.2.2 Strain Rate Effect.......................................................

2.3 Flexure Mechanism..........................................................

2.4 Shear Mechanism.......................................................... 13

2.5 Impact Behaviour of RC Beams......................................... 17

2.6 Previous Research on RC Beams Under Impact Loading........................ 20

3 EXPERIMENTAL INVESTIGATION........................................ 27

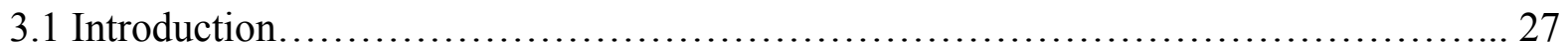

3.2 Test Specimens...................................................... 27

3.2.1 Detail of Specimens.................................................. 28 
3.2.2 Details of HS-RC Series....................................................... 30

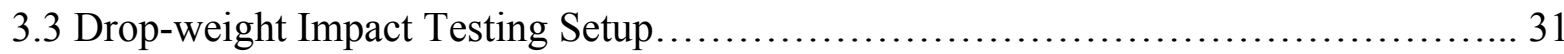

3.3.1 Drop-weight impact frame...................................................... 33

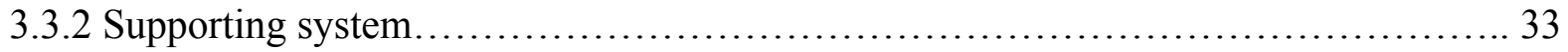

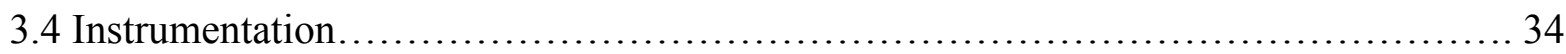

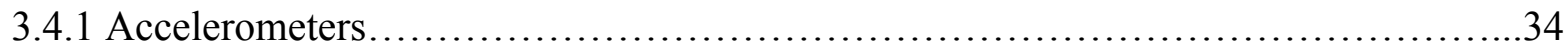

3.4.2 Quartz Dynamic Load Cells..................................................... 35

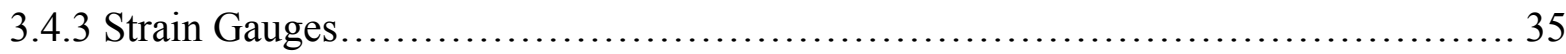

3.4.4 Displacement Laser Sensor................................................ 36

3.4.5 Data Acquisition System.................................................. 37

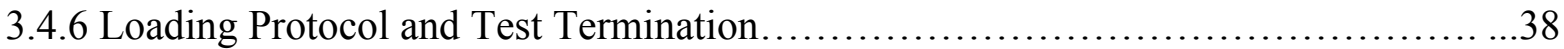

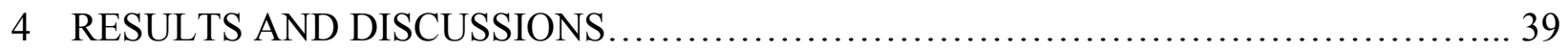

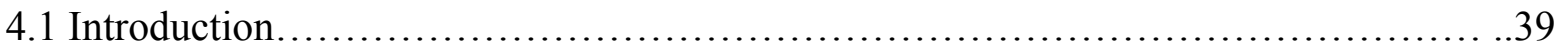

4.2 Materials Mechanical Properties......................................................39

4.2.1 High-Strength Concrete Properties............................................. 39

4.2.2 Steel Reinforcement Properties.............................................. 41

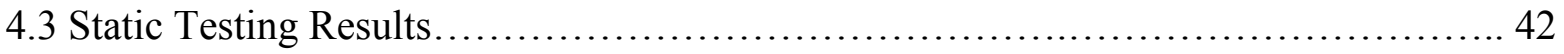

4.3.1 Static Testing Measurements............................................... 42

4.3.2 Crack Pattern of Static Test................................................. 43

4.4 Drop-Weight Impact Testing Results............................................44

4.4.1 Characteristics of Impact and Reaction Forces......................................44

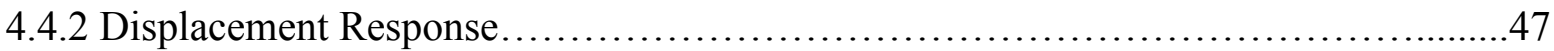

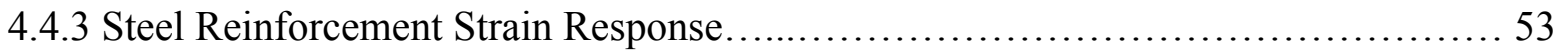


4.4.4 Damage Characteristics and Crack Patterns..................................55

5 CONCLUSION AND RECOMMENDATION ......................................58

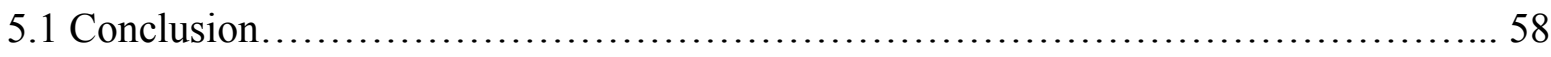

5.2 Drop-Weight Impact Testing Summary and Conclusions...................... 58

5.3 Recommendation for Future Work .........................................60

Appendix A: Beam Design Calculations.................................................61

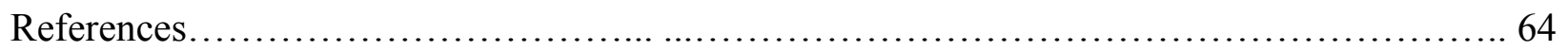




\section{LIST OF TABLES}

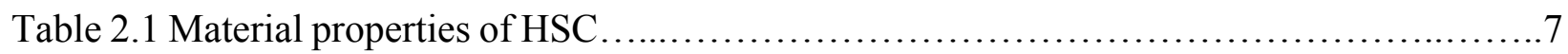

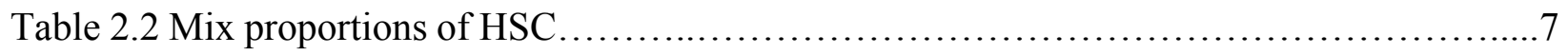

Table 3.1 Steel reinforcement details and static capacities of HSC specimens..................29

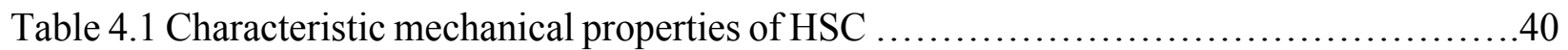

Table 4.2 Characteristics properties of steel reinforcement $\ldots \ldots \ldots \ldots \ldots \ldots \ldots \ldots \ldots \ldots \ldots \ldots . . .41$

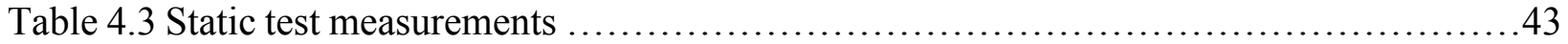

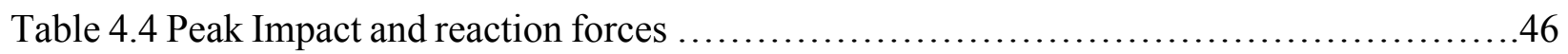

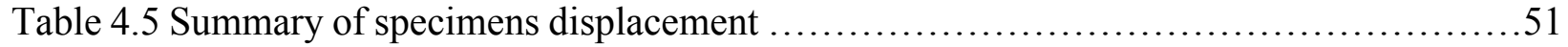

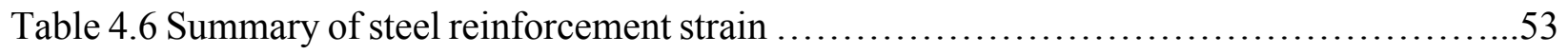

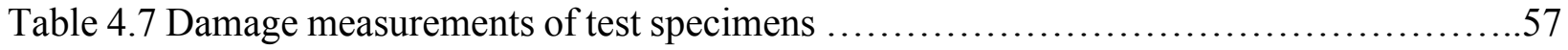




\section{LIST OF FIGURES}

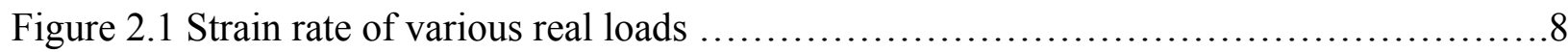

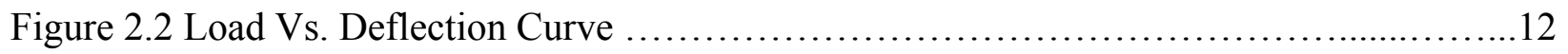

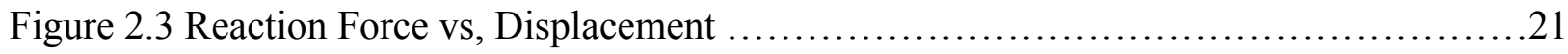

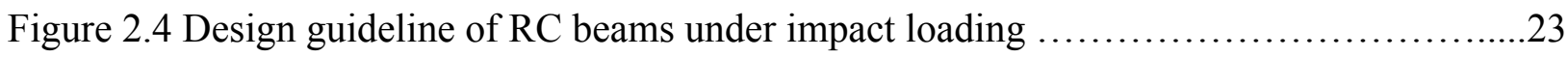

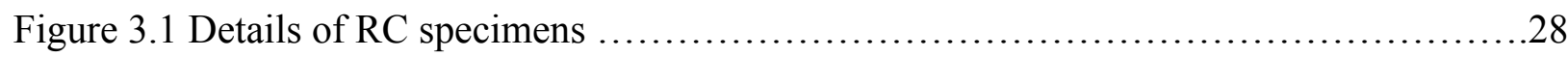

Figure 3.2 Manufacturing and casting of HSC specimens series ............................29

Figure 3.3.a Manufacturing of HS-RC test beams - Formwork \& rebar preparation ...............30

Figure 3.2.b Manufacturing of HS-RC test beams - Casting of reinforce HSC beam...............31

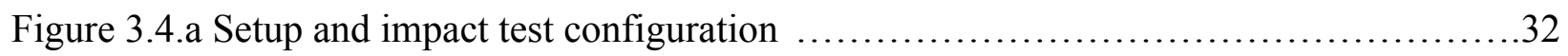

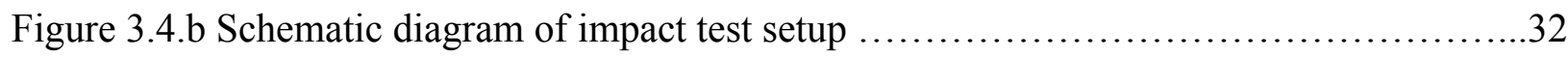

Figure 3.5.a End supports arrangements of the beam specimen under testing ..................33

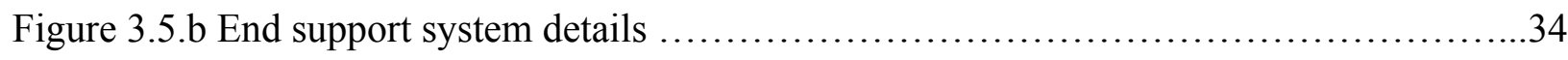

Figure 3.6 Installed strain gauge on steel reinforcement ................................... 36

Figure 3.7 Laser displacement sensors placement f........................................ 37

Figure 4.1 Characteristic mechanical properties of HSC ..................................40-41

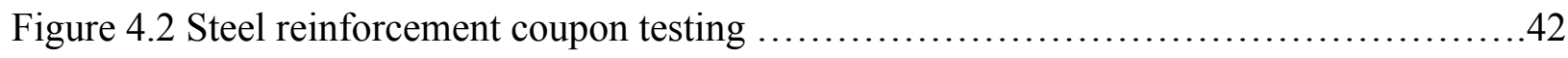

Figure 4.3 Static midspan load-displacement responses ....................................43

Figure 4.4 Crack pattern for beams tested under static loading conditions ....................44

Figure 4.5 Impact and reaction forces-time histories ....................................45

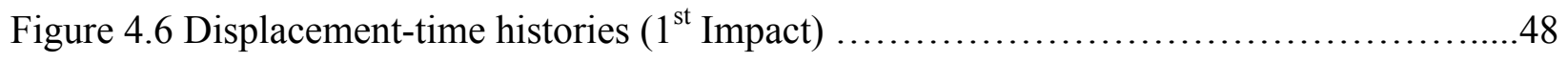


Figure 4.7 Mid span displacement-time histories at different damage levels

Figure 4.8 Effect of steel reinforcement ratio on mid span displacement .50

Figure 4.9 Effect of span on mid span displacement 50

Figure 4.10 Deformed shape under successive impact load of D-3.9-A. .52

Figure 4.11 Strain time history of D-3.9-B. .54

Figure 4.12 Final crack patterns of beam specimens with a $3.9 \mathrm{~m}$ span .56

Figure 4.11 Final crack patterns of beam specimens with a $5.1 \mathrm{~m} \mathrm{span}$ .57 


\section{LIST OF ABBREVIATIONS}

RC: Reinforced Concrete

a: Shear span

d: Shear depth

a/d: shear span to depth ratio

W/C: Water to cement ratio

HRWRA: High-range water reducing admixtures

HSC: High strength concrete

NSC: Normal strength concrete

ASCE: American society of civil engineers

ACI: American concrete institute

$\mathrm{M} / \mathrm{V}$ : Moment to shear ratio

DIF: Dynamic increase factor

CSA: Canadian standards association

HSS: Hollow steel section

ASTM: American standard test method 


\section{CHAPTER 1}

\section{INTRODUCTION}

\subsection{Background}

The overwhelming increase in development of infrastructure over the past few decades has led to higher use of reinforced concrete (RC) members in structures due to its wide availability all over the world. Sometimes these structural members such as beams, columns and slabs are subjected to impact loadings caused by objects striking the RC member of the structure. Examples of these loading cases are vehicle impact in parking lots and industrial plants, iceberg impact on offshore marine structures and many more. It is imperative for structural design engineers to understand the behavior and performance of RC structural members under impact loadings, in order to be able to provide a reliable design for impact loaded structures.

In order to understand and predict the behavior of impact loaded RC members for design purposes, it is imperative to incorporate theoretical analysis with related experimental work and results. Experiments by various researchers have been undertaken in this field, which revealed that failure mechanism and ductility play an important role in the structural response of a RC member under impact loading. These experiments also revealed that the behavior of RC members under impact loading is substantially different from static loading.

Various design factors should be incorporated into experimental work to be able to distinguish the influence of each of these factors on the structural response under impact loading. The effort on providing an empirical formula has been ongoing, since it is a difficult task to provide a formula 
which accounts for all design factors contributing to the response of structures under impact loading. By having a well-organized experimental program, which would encompass all main design factors influencing the response under impact loading, an insight to performance guideline of RC members under impact loading will be possible to achieve.

\subsection{Objective and scope}

The main objective of the present research is to investigate the effects of longitudinal reinforcement ratio and shear span to effective depth ratio on impact behavior of HSC beams. In this research, an experimental program has been developed to analyze and evaluate the behavior and response on $\mathrm{RC}$ beams under impact loading. Impact loading is achieved by using a drop weight loading setup. Two research design parameters have been considered as the main focus criteria in the experimental program. These two parameters consist of shear span to effective depth ratio and longitudinal reinforcement ratio.

\subsection{Research Boundaries}

The present research only considers the dynamic response of RC beam only subjected to low velocity drop weight impact. The overall dynamic response of the $\mathrm{RC}$ beam under impact loading is studied with variation in two design parameter previously mentioned.

The present research is limited to reinforced HSC beam members only. The RC beam specimens tested in the experimental program, are simply supported and loaded at mid span using drop weight loading regime. 


\subsection{Outline of the Research Report}

The structure of this thesis follows the methodology used in establishing the research program. This publication is divided into the following five chapters.

Chapter one presents a brief introduction to identify the problems, scope, and the outline of the research program.

Chapter two provides the fundamental basics and background information related to the present work with a focus on mechanical properties of concrete, strain rate effect, response of RC beams to impact loading.

Chapter three describes the static and drop-weight low-velocity impact investigation of full-scale $\mathrm{RC}$ beams. This chapter reports the details of concrete mix, test specimens, developed impact test setup, instrumentations, and loading protocol that have been utilized in the experimental program of RC beams.

Chapter four presents the drop-weight impact testing results in both. Selected results are presented to characterize the influence of studied parameters on the impact response and failure pattern of the tested plates.

Chapter five presents the main findings and conclusions of the experimental investigations. This chapter also includes recommendations for future studies. 


\section{Chapter 2}

\section{Literature Review}

\subsection{Background of concrete beams}

In order to understand the behavior of RC beams under high strain and dynamic loadings, it is imperative to have extensive knowledge about the static behavior of RC beams so that a reference line of knowledge is established. Reinforced concrete beams have different mechanisms under shear and flexural loadings. Flexural behavior of RC beams is discussed followed by a discussion on their shear behavior.

Shear and flexure loading effects on concrete beams are related, in a way that shear force could be considered as an internal force produced by flexure which is parallel to the cross section of the beam, whereas flexure acts parallel to the longitudinal axis and perpendicular to the section of the beam. Before the concrete beam is cracked, the beam acts as a homogeneous and elastic member. However, the behavior of cracked concrete beam is only applicable for design purposes. Concrete beam cracks once the tensile stress reaches the value of modulus of rapture. The crack occurs at the bottom portion of the beam due to existence of maximum flexural tensile stress in that region. First cracks to occur in a reinforced concrete beam are vertical flexural cracks at the mid span location. The extent of these flexural cracks are mainly effected by the longitudinal flexural reinforcements and concrete strength. Cracks developed by shear effects are caused by tensile stresses in the beam, which are inclined and referred to as diagonal tension cracks. These inclined diagonal cracks usually occur at an angle of approximately 45 degrees. Depending on the extent 
of these diagonal cracks, a brittle failure can occur. Failure mode of concrete beams has significant role in design purposes, as designers wish to have a controlled ductile failure rather than a sudden brittle failure which can be catastrophic. [1]

Typically, reinforced concrete beams may fail under three modes which are flexural failure, diagonal tension failure and shear compression failure. Depending on the design of the reinforced concrete beam, diagonal tension and shear compression failure occur in beams with shear controlled mode of failure. Few factors which affect the failure mode of concrete beams under point loading are the amount of longitudinal reinforcement, tensile strength of concrete, yield strength of the steel and the shear span/depth ratio (a/d). Shear span (a), is the distance between the location of point load to the face of the support. The shear depth (d), is the effective depth of the beam section. The a/d ratio has a direct relation with the flexural/shear stress ratio. Concrete beams with an a/d ratio between 1 to 2.5 are considered short beams and beams with an a/d ratio greater than 2.5 are considered normal or long beams. Normal or long beams $(2.5<\mathrm{a} / \mathrm{d}<5.5)$ can either fail under flexure or shear in the mode of flexural failure or diagonal tension failure respectively while short beams $(1<\mathrm{a} / \mathrm{d}<2.5)$ typically fail in shear under shear compression failure mode. [1]

Concrete beams with large a/d values will be more likely to fail in flexure due to presence of higher flexural stress in comparison to shear stress. Typically, beams with an a/d value greater than 5.5 fail under flexure. Flexural failure is either steel-controlled or concrete controlled depending on the design parameters. Steel-controlled flexural failure is caused by longitudinal steel reinforcement yielding, which is the most desirable due to ductile behavior and large deformations sustained by the beam. [1] 
Reinforced concrete beams with an a/d ratio between 2.5 to 5.5 would either fail in diagonal tension failure or flexural failure mode. Diagonal tension failure is a brittle failure mode and occurs suddenly right after the development of the diagonal cracks. Diagonal tension failure is initiated by a few fine vertical cracks at the mid span location, which causes a decrease in the bond strength of the longitudinal steel reinforcement and the concrete at the support locations. Consequently, few inclined cracks occur in the area of the vertical flexural cracks or as an extension of them and then propagate close to support areas which are known as flexure-shear cracks. Eventually, one of the inclined cracks keeps widening and becomes the principal diagonal tension crack. The principal crack then extends from the bottom to the top of the beam inclining towards the point load location at the top surface, which ultimately leads towards sudden and brittle global failure of the whole beam. One of the few parameters which affect the development of the diagonal tension cracks is the shear steel reinforcement. [1]

Shear compression failure occurs in concrete beams with an a/d ratio between 1 to 2.5 . This failure mode is slightly similar to diagonal tension failure which is initiated by few fine vertical cracks at mid span location. However, the crack propagation stops as the decrease in bond strength of longitudinal steel reinforcement and concrete at support area occurs. Afterwards, an inclined crack with an angle steeper than 45 degrees suddenly occurs, which then extends from the bottom of the beam towards the neutral axis. Consequently, the concrete in the zone above the inclined crack crushes and then the beam fails once the the inclined crack joins the crushed concrete zone. Shear compression failure is less brittle than diagonal tension failure due to redistribution of stresses in the concrete compression zone. [1] 


\subsection{High strength concrete material}

The main distinction of high strength concrete from normal strength concrete is the higher compressive strength. However, some mechanical and chemical variety exists. A typical high strength concrete mix proportion and material properties are presented in tables 2.1 and 2.2.

Table 2.1 - Material properties of HSC [14]

\begin{tabular}{|c|c|c|c|c|}
\hline $\begin{array}{c}\text { Density, } \\
\mathrm{kg} / \mathrm{m}^{3}\end{array}$ & $\begin{array}{c}\text { Compressive strength } \\
f_{c}^{\prime}, \mathrm{MPa}\end{array}$ & $\begin{array}{c}\text { Elastic modulus } \\
E_{c}, \mathrm{GPa}\end{array}$ & $\begin{array}{c}\text { Flexural strength } \\
f_{r}, \mathrm{MPa}\end{array}$ & $\begin{array}{c}\text { Splitting Strength } f_{\text {tsp, }}, \\
\mathrm{MPa}\end{array}$ \\
\hline 2540 & 83.1 & 30.2 & 8.0 & 4.5 \\
\hline
\end{tabular}

Table 2.2 - Mix proportions of HSC [14]

\begin{tabular}{|c|c|c|c|c|c|}
\hline Cement & Silica fume & Fine sand $(0.5 \mathrm{~mm})$ & Coarse aggregate $(12 \mathrm{~mm})$ & HRWRA & Water \\
\hline $450 \mathrm{~kg} / \mathrm{m}^{3}$ & $30 \mathrm{~kg} / \mathrm{m}^{3}$ & $550 \mathrm{~kg} / \mathrm{m}^{3}$ & $1100 \mathrm{~kg} / \mathrm{m}^{3}$ & $20 \mathrm{~kg} / \mathrm{m}^{3}$ & $220 \mathrm{~kg} / \mathrm{m}^{3}$ \\
\hline
\end{tabular}

High strength concrete contains a low water to cement ratio (W/C) and silica fume which is substantially the reason for higher compressive strength. Use of high-range water reducing admixtures (HRWRA) are required to provide enough workability during casting. Higher elastic modulus in HSC is a result of the higher compressive strength, which leads to improvement of flexural rigidity and reduction of deflection. [15] The increase in compressive strength also results in a higher flexural strength. However, higher compressive strength leads to lower tensile to compressive strength ratio, which indicates that higher compressive strength does not majorly improve tensile strength. [16] 


\subsubsection{Tension properties of high strength (HS) concrete}

Ductility of concrete is related to cracking and post-cracking behavior which are governed by the tensile properties. It is evident that an increase in the compressive strength, slightly increases the tensile strength with a smaller rate. The brittleness of HSC causes a rapid loss in its stress-carrying capacity after the peak tensile stressed and been reached. [6]

\subsubsection{Strain rate effects}

Concrete structures behave differently under various strain rates. High strain rates imposed on concrete structures are caused by natural sources such as tornados, earthquakes and ocean wave, or accidents such as explosions and impacts. [9]

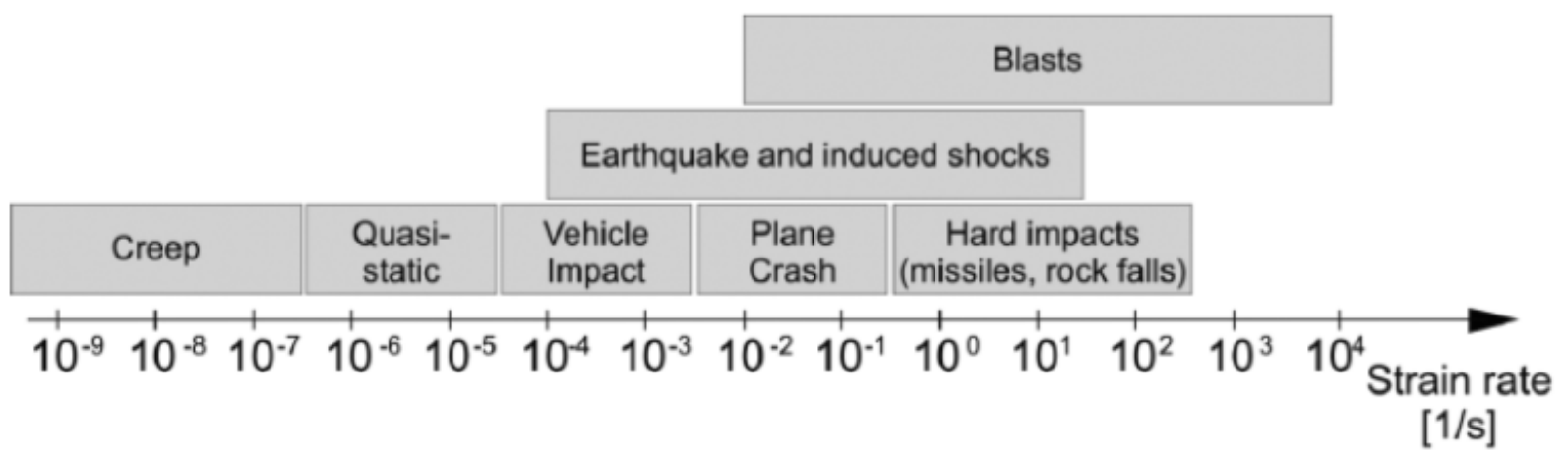

Figure 2.1 - Strain rate of various real loads [9]

The effect of strain rate on material strength is usually presented by a DIF versus strain rate graph.

The dynamic increase factor (DIF) is the ratio of dynamic strength to the quasi-static strength. [9]

High strain rate loadings with strain rates ranging from $10 \mathrm{~s}^{-1}$ to $1000 \mathrm{~s}^{-1}$, tend to significantly

increase the material strength of concrete. Concrete compressive and tensile strengths can increase by more than $100 \%$ and $600 \%$ respectively under high strain rate loadings. [7] 
The compressive and tensile strains rate sensitivities are similar to low strain rates, and the difference in sensitivity occurs at high strain rates. The concrete strength also does not affect the strain rate sensitivity of the concrete. [9]

High strain rate loadings with strain rates ranging from $10 \mathrm{~s}^{-1}$ to $1000 \mathrm{~s}^{-1}$, tend to significantly increase the yield stress of reinforcing steel by more than $60 \%$, depending on the steel grade. When the material is loaded statically with a quasi-static strain rate, the bar elastically deforms until the upper yield stress is reached. The bar will remain at the lower yield stress for a while until strain hardening takes place and continues until the steel bar reaches the ultimate stress and strain. All of the steel bar have the same strain at the ultimate point. Beyond the ultimate point, the stresses will localize in one location and cause necking to take place, while the rest of the steel bar is elastically unloaded. Under high strain dynamic loading, the yield and ultimate stresses of the steel bar increases. However, the increase in the ultimate stress is minor in comparison to the increase in yield stress and only increase up to $5 \%$. The dynamic increase factor (DIF) for yield and ultimate stress are both inversely related to the yield stress of the steel bar. [8]

\subsection{Flexure Mechanism}

The flexural mechanism is also somewhat different compared to normal strength concrete. Due to brittleness associated with HSC, ductility of HSC beams is of major concern to design engineers. [5]

Flexure or bending exists in beams externally loaded in a perpendicular direction to beam, and is associated with deflection in the same direction of the applied load. In the case of external load applied on the top of the beam, the top portion is subjected to compression whereas the bottom portion is subjected to tension. Cracking occurs upon reaching the tensile strength of concrete in 
the maximum flexure region. Steel reinforcement is utilized in the bottom portion of the beam to improve the flexural resistance of them resulting in higher tensile capacity. Materials of reinforced concrete beams are characterized by the compressive strength $\left(f_{c}^{\prime}\right)$ and tensile strength of the concrete and yield strength of the steel $\left(f_{y}\right)$. Tensile strength of concrete is represented by the modulus of rapture $\left(f_{r}\right)$. Flexural behaviour of properly reinforced concrete beam consists of uncracked elasticity, cracked elasticity, tension steel yielding and failure. [1]

At very small loads which cracking has not occurred, concrete behaves as an elastic uncracked section. The stress and strain distribution linearly increases from the neutral axis to the top and bottom of the section, which has a value of zero at the neutral axis and reaches the maximum at the top and bottom fibers. At this stage, tension is resisted by both steel and concrete, while compression is resisted by part of the concrete section above the neutral axis. The strain in both concrete and steel are equal at the location of reinforcements, while the stress in steel $\left(f_{s}\right)$ is higher than the stress in concrete $\left(f_{c}\right)$. [1]

Cracking takes place as the flexural stresses exceed the tensile strength of concrete $\left(f_{r}\right)$. The concrete cannot resist tensile stresses anymore and all the tensile stress is resisted by the steel reinforcement only. The concrete has an elastic cracked behavior at this stage. Due to cracking, the neutral axis shifts upwards and results in a decrease of the concrete compression zone. However, concrete will keep resisting the compressive stresses and a maximum compressive stress of $f_{c}^{\prime} / 2$ is induced. The elastic cracked behavior of concrete takes place at the service load stage, and the stress and strain distribution of steel and concrete is still linear. [1]

The yield stress in steel reinforcement $\left(f_{y}\right)$ is reached as the loading increases. Deformations of the beam increase quickly as the steel reinforcement reaches yield point while the increase of flexural bending forces is not significant. At this stage, the concrete compressive stresses are still 
elastic and the beam is able to carry the increase in applied loads. However, the yielding of steel reinforcement marks the initiation of beam failure. [1]

The failure of the beam occurs by the increase of load after yield point of reinforcement steel, which is accompanied by very large deformations. At this stage, the tensile strain of steel $\left(\varepsilon_{s}\right)$ is higher than the yield strain $\left(\varepsilon_{y}\right)$, whereas the steel reinforcement stress is equal to yield stress $\left(f_{s}=\right.$ $\left.f_{y}\right)$. The compressive stress in concrete is equal to $\left(f_{c}^{\prime}\right)$, while its compressive strain $\left(\varepsilon_{c}\right)$ reaches or exceeds 0.0035. [1]

Reinforced concrete beams subjected to flexure loading fail under two modes of steel-controlled failure mode and concrete-controlled failure mode, which are initiated by yielding of tension reinforcement and crushing of concrete, respectively. The state between the steel-controlled and concrete-controlled is known as balanced condition, where the tension reinforcements yields and the concrete crushes simultaneously. The flexural failure modes are highly dependent on the amount of tension reinforcement and the material properties of concrete and steel.

Steel-controlled failure is also known as tension failure, where the tension reinforcing steel yields with a strain equal or greater than the yield strain of steel $\left(\varepsilon_{y}\right)$ at a stress equal to the yield stress of steel $\left(f_{y}\right)$, while the compressive strain of concrete reaches $0.0035\left(\varepsilon_{\text {cmax }}\right)$. The steel-controlled failure mode tends to be a ductile failure since the beam is able to deform significantly before the occurrence of failure.

The concrete-controlled failure is also known as compression failure, where the compressive concrete strain reaches its maximum $\left(\varepsilon_{c \max }=0.0035\right)$ value before the yielding of tension reinforcing steel. [1]

The balanced condition failure mode occurs where the beam is intermediately reinforced (balanced reinforcement) which is accompanied by immediate crushing of concrete yielding of 
reinforcing steel where the strain and stress values of steel are equal to the yield values ( $\varepsilon_{s}=\varepsilon_{y}$ , $f_{s}=f_{y}$ ). The compressive strain of concrete also reached its yield limit which results in crushing of concrete in the compression zone $\left(\varepsilon_{\operatorname{cmax}}=0.0035\right)$. The balanced condition failure mode is between the steel-controlled failure and concrete-controlled failure modes. This failure mode features both ductile and brittle behaviors, the beam behaves elastic until the maximum load is reached and then a sudden brittle failure occurs. The balanced condition failure mode is also known as a case of concrete-controlled failure. [1]

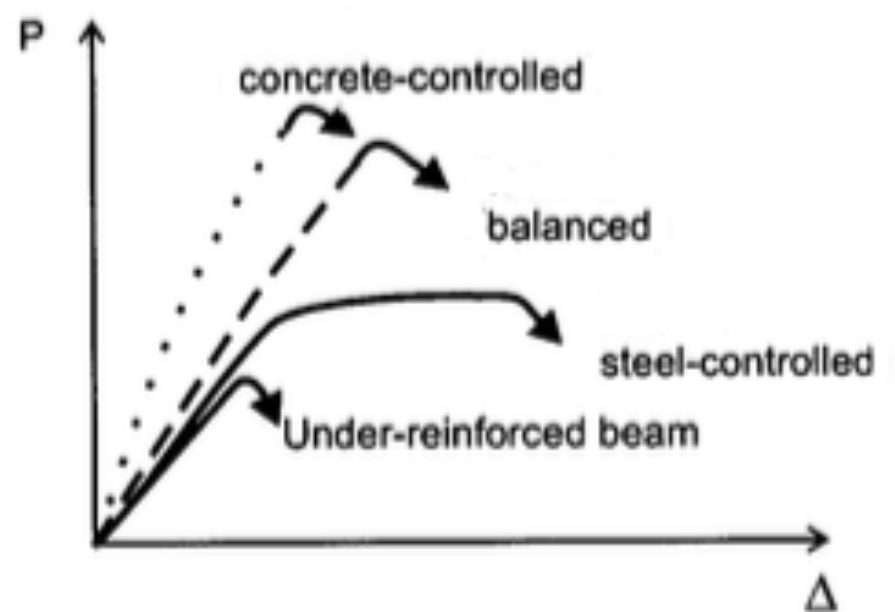

Figure 2.2 - Load Vs. Deflection Curve [1]

High strength concrete (HSC) behaves somewhat differently compared to normal strength concrete (NSC). Due to different material properties, flexure behavior is also different. Brittleness and compressive strain capacity of HSC is lower than of NSC. Compressive strain capacity is the strain at which crushing is initiated in concrete. Ductility is the ability of a structural member to deform at or near its failure load without a drastic strength loss. Higher concrete strength increases the ductility up to a concrete strength of $105 \mathrm{MPa}$, and beyond this limit the ductility decreases. Lower tensile reinforcement ratio leads to higher ductility since yielding of the steel reinforcement is 
facilitated and allows the structural member to deflect upon failure of concrete rather than the steel. In accordance to ACI Code, The tensile reinforcement ratio $(\rho)$ in a flexural member should be limited to 0.75 of the balanced steel ratio $\rho_{\mathrm{bs}}$ in normal cases and to $0.5 \rho_{\mathrm{bs}}$ in cases where the flexural system is subject to moment redistribution. In case of high strength concrete, the value of $\rho$ should be decreased with the increase in concrete strength. The value of Compression reinforcement allows the reduction of neutral axis thus increasing the ductility of the beam upon failure, and also results in confining of the compression concrete with the help of steel ties. The improvement in ductility is a function of both the amount of compression steel reinforcement and tie spacing. However, confinement of concrete is less effective in HSC in comparison to NSC. [5]

\subsection{Shear mechanism}

Upon cracking of the concrete, the internal shear load transfer mechanism in the beam differs substantially. Before the occurrence of cracks in concrete beams, the entire shear force is carried and resisted by the concrete shear force $\left(V_{c}\right)$ only.

According to American Society of Civil Engineers-American Concrete Institute (ASCE-ACI 1973), upon the development of the inclined cracks, only up to $40 \%$ of the shear force imposed on the concrete beam is resisted by the $\left(V_{c}\right)$ in the compression zone, while the remainder of the shear force is resisted by the vertical component of interface shear force $\left(V_{a y}\right)$ and the dowel-shear force $\left(V_{d}\right)$ which account for $33 \%$ to $50 \%$ and $25 \%$ to $50 \%$ of the entire shear force imposed on the beam, respectively. The interface shear force $\left(V_{a}\right)$ is tangentially transmitted across the crack by aggregate interlocking and become less effective as the cracks widen. The dowel-shear force $\left(V_{d}\right)$ is developed by the dowel action of the longitudinal steel reinforcement crossing the cracks, and once interface shear force $\left(V_{a}\right)$ becomes less effective, more shear force is then resisted by $V_{d}$ 
component and causes splitting cracks to occur along the reinforcement which leads to complete loss of dowel-shear force $\left(V_{d}\right)$. Consequently the entire shear force is resisted by $V_{c}$ in the compression zone above the crack vicinity, which then leads to crushing of concrete at the area of the point load location. [1] Majority of the beam shear resistance is provided by the concrete shear resistance $\left(V_{c}\right)$, which is affected by: shear span/depth ratio, longitudinal steel reinforcement ratio, axial forces, beam size and tensile strength of concrete. [2]

Tensile strength of concrete affects the load level which inclined cracking occurs. As mentioned before, diagonal tension cracking takes place once the tensile stresses supersede the tensile strength of the concrete. Compressive axial forces tend to increase the shear strength of concrete, whereas the tensile axial forces tend to decrease it. [1]

Since the shear resistance of reinforced concrete beams is highly limited to the concrete shear resistance $\left(V_{c}\right)$, it is necessary to enhance the shear resistance of the concrete beams by means of providing steel shear reinforcements in the case of application of shear loads higher than the concrete shear resistance. Use of steel shear reinforcement prevents the occurrence of brittle and sudden shear failure mode in concrete beams. Shear reinforcements have the most effect acting perpendicular to the inclined cracks, but typically they are provided vertically due to difficulty of installing them at an angle. Shear reinforcement comes into action after the inclined cracking has occurred, since the cracks open and develop tensile stresses in the shear reinforcement. As the applied load increases and the inclined diagonal cracks become wider, the tensile stresses in the shear reinforcements increase which enhances the shear resistance of the beam. The developed tensile forces in the shear reinforcement are denoted as $\left(V_{S}\right)$. Reinforced concrete beams with shear reinforcements have three possible shear controlled failure modes as it follows: shear compression failure mode, sudden shear compression failure mode and diagonal tension failure mode. [1] 
The shear compression failure mode occurs in beams with moderate amount of shear reinforcement, which is the most desirable failure mode since it is not sudden. After the inclined cracking has occurred, both the concrete compression zone and shear reinforcement resist the imposed shear loads until the shear reinforcement reach yield point. After the tensile yielding of the shear reinforcement, the excess shear force caused by increase in the applied load is resisted by the concrete compression zone only. The concrete beam fails once concrete crushing takes place in the compression zone due to compression and shear stresses. The tensile yielding of the shear reinforcement allows widening of the diagonal cracks, hence preventing a sudden failure mode. [1]

The sudden shear compression failure mode occurs in beams with large amount of shear reinforcement. The yielding of the shear reinforcement does not take place due to large amount of shear reinforcement and redistribution of shear stresses among more steel, therefore the concrete crushes suddenly in the compression zone resulting in a sudden shear compression failure mode. [1]

The diagonal tension failure mode occurs in long beams with a large a/d value which contain little shear reinforcement. Due to little amount of shear reinforcement and shear stress concentration among them, the tensile yielding of the shear reinforcement takes place immediately after the inclined cracking occurs. Therefore, concrete crushing happens quickly since there is no shear force distribution between the concrete and the steel, and the beam fails suddenly with no warning. [1]

The presence of the shear enforcement does not prevent shear controlled failure. The shear controlled failure is prevented only if the flexural failure is initiated beforehand. However, the shear reinforcement prevents the sudden failure by preventing the penetration of inclined cracks 
into the concrete compression zone. Shear reinforcement also enhances the shear resistance of the beam by redistribution of shear forces due to imposed tensile stress on the shear reinforcement after the inclined cracking takes place. [1]

High strength concrete (HSC) behaves somewhat differently compared to normal strength concrete (NSC). Due to different material properties, shear mechanism of high strength concrete beams is also different. The higher early age shrinkage, brittleness and smoothness of crack surfaces are all associated with the increase in compressive strength of concrete. The early age shrinkage in high strength concrete is caused by self-desiccation due to higher hydrating material and lower water cement ratio of the concrete material, which also leads to development of fine voids in the material matrix. Early age shrinkage leads to deterioration of shear strength at diagonal cracking area of the beam. The shear resistance provided by dowel action of longitudinal reinforcements is also reduced due to crack development around the reinforcement and degradation of the bond stiffness. Due to brittleness of HSC, the shear resistance of the compression zone at the uncracked stage is lower. The smooth crack surface of HSC beams lowers the shear resistance by reducing the aggregate interlocking. In HSC beams, the cracks penetrate through the aggregate, which provides a smooth crack surface with little interlocking capacity. [3]

The shear strength of concrete beams does not improve beyond a certain range with the increase in concrete compressive strength. However, in the case of HSC beams with steel shear reinforcement, the beam fails in diagonal tension rather than in shear compression failure, which indicates the higher effect of shear reinforcement. There is a linear relation between the ultimate behavior of the beam and the amount of shear reinforcement provided. The influence of shear reinforcement on HSC beams with moderate flexural reinforcement is higher than of a HSC beam with high flexural reinforcement. However, higher amount of longitudinal reinforcement increases 
the shear strength of HSC beams with shear reinforcements. Accordingly, a higher moment/shear ratio $(\mathrm{M} / \mathrm{V})$ results in a lower failure shear stress. Higher amount of shear reinforcement reduces diagonal crack width, which results in higher shear strength contribution of concrete. However, the shear reinforcement becomes less effective as their amount increases. [4]

\subsection{Impact behavior of RC beams}

When an object collides with a target with high velocities of 40-300 m/s, the impulse of the load acts over a short period of time, and the RC structure has no time to globally respond and local failures usually take place in form punching or spalling. The crack pattern of failed RC structures under impact, suggests the existence of both flexural and shear failures. However, impactors with velocities over $1000 \mathrm{~m} / \mathrm{s}$ always result in local failures. Due to the short application time of impact loadings, support conditions have limited effect on impact response, failure pattern and impact capacity RC structures. [13]

Reinforced concrete structures that are imposed to high strain rate loadings, should be designed to fail under flexure mode. This is due to the fact that flexural failure occurs with warning signs such as deflections before total failure, and it is safer than the brittle shear failure with little or no warning signs. Resistance of flexural failure type RC beams towards high strain loadings can be approximated using the static flexural capacity. Design of RC beams for impact resistance may be done using the relationship of static bending capacity, residual displacement, maximum reaction force, applied and absorbed energy. However, the same does not apply to shear failure type RC beams. [10]

Shear mechanisms of RC beams effect the overall impact behavior of the structure. Upon the impact of an object toward the RC beam, the induced impact force is initially resisted by beam's 
stiffness, while it accelerates in the direction of the induced impact force. The RC beam's acceleration develops inertia forces towards the opposite direction, which are equal to mass multiplied by the acceleration integrated over the volume. The remained of the impact force will be transmitted to support locations and resisted by support reactions. Higher inertia forces reduce the value of the mid span moment, since there will less remainder of the impact force to be resisted by reaction forces. The same does not affect the mid span shear force, and is always equal to half of the impact force. The RC beam undergoes the same shear force but smaller flexural forces than it would statically, therefore majority of RC beams become shear critical under impact loading.

When RC beams are exposed to high strain loadings, plastic hinges may be developed at critical sections of the beam. It is imperative that the plastic hinge exhibits a good flexural ductility so that it can the absorb the excessive energy by inelastic deformation before loss of resisting moments. Flexural ductility of RC beams monotonically decreases with the increase of tensile reinforcement ratio. Lower tensile reinforcement ratio leads to yielding of tensile reinforcement, resulting in a ductile failure, respectively higher steel yield strength decreases the ductility since it takes longer for the tensile reinforcement to yield and remains elastic, resulting in a brittle and sudden failure. Lower tensile reinforcement ratio only improves flexural ductility of RC beams with ductile failure mode, whereas the tensile reinforcement ratio has no effect on flexural ductility in RC beams with brittle failure mode. Generally, the increase in compression reinforcement ratio results in higher flexural ductility. However, the difference between the tensile and compression ratios should be kept low in order to benefit the improvement of flexural ductility which compression reinforcement provides. The use of high strength steel reduces the allowable limit of the reinforcement difference ratio and may slightly decrease the flexural strength. Major parameters 
affecting the flexural ductility of RC beams are difference of reinforcement ratio $\left(\rho_{t}-\rho_{c}\right)$, concrete strength $\left(f_{c}^{\prime}\right)$ and steel yield strengths $\left(\left(f_{y}\right) \cdot[12]\right.$

Flexural ductility of RC beams is assessed using the curvature ductility factor $(\mu)$, which can be evaluated using the moment curvature curve in term of ultimate and yield curvature $\left(\emptyset_{u}, \emptyset_{y}\right)$.

$$
\mu=\emptyset_{u} / \emptyset_{y}
$$

The ultimate curvature $\left(\emptyset_{u}\right)$ of the section corresponds to the after peak point where the resisting moments have dropped to $85 \%$ of the peak moment. The yield curvature corresponds to the hypothetical yield point of a linearly elastic and perfectly plastic system. The stiffness of the yield curvature is equal to the sectional secant stiffness at $75 \%$ of the peak moment with a yield moment equivalent to the peak moment of the section. [12]

The use of high strength concrete in beams increases the flexural ductility of the beams in ductile failure regions, whereas it reduces the flexural ductility in the brittle failure regions. The allowable reinforcement ratio difference $\left(\rho_{t}-\rho_{c}\right)$ for achieving adequate flexural ductility, increases with the increase in concrete strength. However, the improvement in flexural strength by increasing the difference in reinforcement ratios is insignificant beyond the balanced reinforcement ratio, where the beam exhibits a brittle failure mode. The use of high-strength concrete also increases the flexural strength and allowable reinforcement difference ratio of RC beams regardless of the reinforcement ratio. However, this improvement become less significant with increase in minimum flexural ductility design level $\left(\mu_{\min }\right)$. [12]

The normalized neutral axis depth $\left(d_{n} / d\right)$ increases monotonically with the tensile reinforcement ratio at peak resisting moment, therefore reducing the flexural ductility. Hence limiting the 
normalized neutral axis depth at peak moment is effective in improving flexural ductility of RC beams. The increase in concrete strength significantly reduces the normalized neutral axis depth $\left(d_{n} / d\right)$, whereas the steel yield strength has minor effect. [12]

\subsection{Previous research on $\mathrm{RC}$ beams under impact loading}

A drop-weight impact test program was undertaken by Hughes and Beeby (1982), which consisted of 80 pin-ended and 12 simply supported RC beams. Two various impact objects with masses of $58.5 \mathrm{~kg}$ and $98 \mathrm{~kg}$ were utilized, with an impact velocity range of 2.1-7.9 m/s. Various stiffness of the impact zone was investigated by placing pads with various materials (steel, rubber and plywood).

Majority of the beams failed in flexure mode at the mid-span location. However, two beams which have had less transverse steel reinforcement failed in shear mode at the third point location, which is caused by third mode excitation as a consequence of high shear stress at those locations. The test results led to the conclusion that a higher impact velocity with a stiffer impact zone (steel pad) cause a dominant shear failure mode. [18]

A drop-weight impact test on eight RC beams was conducted by Kishi et al. (2001), in order to establish a rational design guide for beams with flexural failure modes. The specimens were impacted at the mid-span location by a steel impactor with a mass of $200 \mathrm{~kg}$. The results suggested that beams with flexural failure mode can be designed with a margin of safety by considering a dynamic response ratio of 2 , and a ratio of absorbed energy to input kinetic energy of 0.7 . A simple equation has been proposed to evaluate the required static bending resistance of beams under impact loading 


$$
P_{\text {usd }}=0.35 \frac{E_{\mathrm{kd}}}{\delta_{\mathrm{rd}}}
$$

where $\mathrm{P}_{\mathrm{usd}}$ is the static bending resistance, $\mathrm{E}_{\mathrm{kd}}$ is the input kinetic energy and $\delta_{\mathrm{rd}}$ is the residual displacement. The reaction forces versus displacement loop at failure stage are simplified as a parallelogram as demonstrated in the following figure. [19]

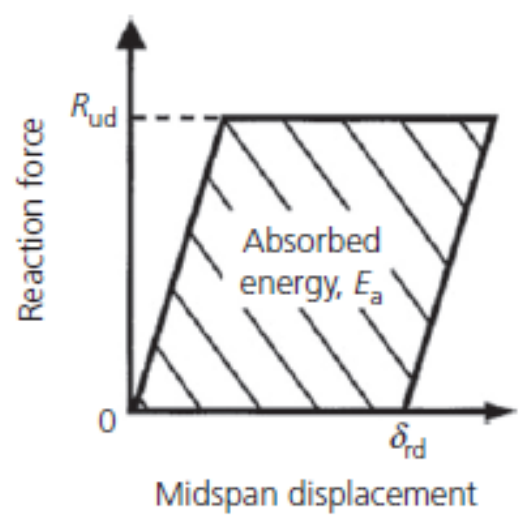

Figure 2.3 - Reaction Force vs, Displacement [19]

Another falling-weight impact test was undertaken by Kishi et al. (2002), which focused on establishing a design guide on shear failure type $\mathrm{RC}$ beams under impact loading. A free falling steel object with a weight of $300 \mathrm{~kg}$ is impacted at the mid-span of RC beams. It is concluded by the authors that the effect of contact surface of the impacting object on the dynamic response and failure modes are minimal under similar impact velocities. Based on the test results, shear failure type RC beams without shear reinforcement shall be designed with a safety margin by considering a dynamic response of 1.5 and an absorbed to input energy ratio of 0.6 . Static shear resistance of RC beams under impact loading are calculated using the following equation 


$$
V_{\text {usd }}=0 \cdot 8 \frac{E_{\mathrm{kd}}}{\delta_{\mathrm{rd}}}
$$

where $V_{\text {usd }}$ is the static shear resistance, $E_{k d}$ is the input kinetic energy and $\delta_{\text {rd }}$ is the residual displacement. [10]

An experimental study is conducted by Fujikake et al. (2009) which consisted of drop-hammer impact test of $12 \mathrm{RC}$ beams. A free-falling hammer with a mass of $400 \mathrm{~kg}$ was dropped at the midspan of beams with four varying falling heights. [20]

Test results suggested that flexural failure type $\mathrm{RC}$ beams with lower longitudinal reinforcement ratio exhibit an overall flexural failure mode, while beams with a higher longitudinal reinforcement ratio also exhibit local failures such as crushing of concrete near the impact point. However, local failure is substantially mitigated by utilizing a high longitudinal compression reinforcement. A higher drop height increases the impact response characteristic s such as the maximum impact load and impulse, duration of impact load, maximum deflection and the time taken for maximum midspan deflection. However, the flexural rigidity of the beams also affected the duration of impact load, maximum mid-span deflection and the time taken for maximum mid-span deflection. [20] Furthermore, a design guideline for RC beams under impact loading was provided as demonstrated in the figure below. 


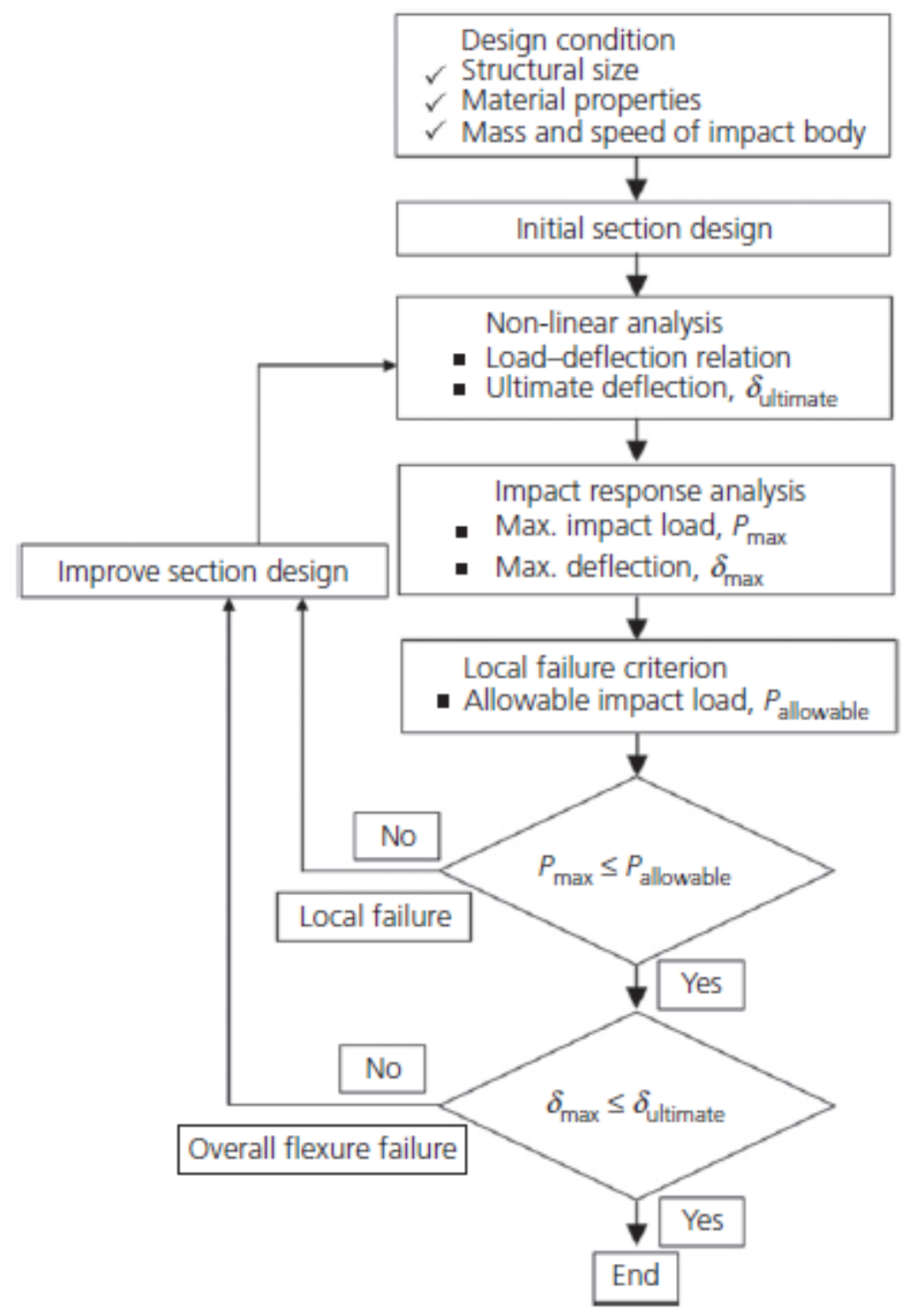

Figure 2.4 -Design guideline of RC beams under impact loading [20]

A test program is designed by Chen and May (2009) to investigate high-mass with low-velocity impact behavior of RC beam. Specimens were impacted with an impactor with a weight of 98.7 $\mathrm{kg}$ with a velocity of $7.3 \mathrm{~m} / \mathrm{s}$. The three variables of the investigation were the support conditions (pin-ended, simply supported), shape of impacting object (flat or hemispherical) and the impact interface (Use of plywood at impact zone or direct contact with impactor). The results suggested 
that support conditions are less influential on the impact force, in comparison to the span length. It is also concluded that use of plywood as an interface had no effect of impact force distribution. [21]

A well instrumented experimental program was undertaken by Saatci and Vecchio (2009) which aimed to establish a better understanding of the effects of shear mechanism on the behavior of RC beams under impact loading. Varying impactor weight of $211 \mathrm{~kg}$ and $600 \mathrm{~kg}$ are used for impact test. All beams developed severe diagonal cracks regardless of their static behavior. The diagonal cracking originated at the impact point and propagated downwards with an angle of 45 degrees, resulting in the development of shear plugs. Hence it is suggested that shear mechanism should be considered in prediction of impact behavior of RC beams. Impact forces are initially resisted by the inertia of the specimen before the forces reach support points. Therefore, the mass and geometric properties of the specimen play an important role in resisting impact forces. [11]

A series of low velocity impact experimental program on $\mathrm{RC}$ beams have been investigated by Tachibana et al. (2010). Experimental specimens varied in span lengths, cross-sections and longitudinal reinforcements. Various steel weights were used as impactors (150,300 and $450 \mathrm{~kg})$. Based on experimental results, An equation has been proposed to evaluate the mid-span deflection of the RC beams according to impact energy and static ultimate flexure resistance

$$
\delta_{\max }=0.522 \frac{E_{\mathrm{col}}}{P_{\mathrm{u}}}
$$

where $\delta_{\max }$ is the maximum displacement $(\mathrm{mm}), \mathrm{E}_{\mathrm{col}}$ is kinetic energy $(\mathrm{J})$ and $\mathrm{P}_{\mathrm{u}}$ is the ultimate flexure resistance $(\mathrm{kN})$. The proposed equation is validated through experimental results and finite element simulations. The static flexural resistance of the tested beams varied from 16.7 to 66.7 
$\mathrm{kN}$, and the impact energy varid from 150 to $5400 \mathrm{~J}$ according to different mass and velocity of the impacting object. [22]

A performance based design methodology for impact resistance of RC beams have been developed by Kishi and Mikami (2012) according to drop-weight impact test results. Three various impactor weights were used (300, 400 and $500 \mathrm{~kg}$ ), with varying impact velocities with the range of 3.1-7.7 $\mathrm{m} / \mathrm{s}$. Flexural cracks were observed in the clear span at the upper section as well as the bottom section. Furthermore, diagonal shear cracks were developed around the mid-span zone, mostly underneath the impact location. The diagonal cracks become prominent with increasing impact velocities. The following design formulas were proposed based on the relationship between maximum and residual deflections per unit input impact energy,

$$
\begin{gathered}
P_{\text {usc }}=0.63 \frac{E}{D_{\max }} \\
P_{\text {usc }}=0.42 \frac{E}{\delta_{15}}
\end{gathered}
$$

where $P_{\text {usc }}$ is the static flexural load carrying capacity $(\mathrm{kN}), \mathrm{E}$ is the input impact energy $(\mathrm{J}), \mathrm{D}_{\max }$ is the maximum displacement and $\delta_{\mathrm{rs}}$ is the residual displacement $(\mathrm{mm})$. The proposed equations allow for a simplified design approach for structures exposed to impact loading. However, the equation is limited to certain factors such as an input impact energy less than $15 \mathrm{~kJ}$, Static flexural load carrying capacity less than $240 \mathrm{kN}$ and static shear flexural capacity ratio value larger than 1.5. [23] 
Adhikary et al (2015), conducted an impact test program consisting of $30 \mathrm{RC}$ beam. The program was intended to examine the impact response and failure modes of RC beams. The test results suggested that no shear failure occurs under impact loading in statically flexure-critical beams (i.e. shear to bending ratio greater than one). However, with the increase of drop height, more localized failure with extensive concrete crushing occurs within the impact zone. On the contrary, transition in the mode of failure of RC beams from flexural failure at static loading to shear failure at low velocity impact has been concluded in the literature (Hughes and Beeby, 1982; Saatci and Vecchio, 2009). However, this change of failure mode was not observed in the experimental program undertaken by Adhikary et al. (2015). A harder and stiffer impact interface zone which results in a higher inertia force. For instance, use of steel plate at the impact contact surface results in the transfer of majority of the impact energy through the steel plate. This transfer of energy accelerates the beam in the direction of the impact force which generates more inertia force. The higher inertia force promotes shear failure under impact loading. However, in the experimental program undertaken by Adhikary et al. (2015), the impacting object had a direct contact with the beam surface, causing majority of the impact energy to be dissipated during localized crushing of concrete in the impact zone, therefore generating less inertia force due to lower energy transfer to the entire span of the beam. [24] 


\section{Chapter 3}

\section{EXPERIMENTAL INVESTIGATION}

\subsection{Introduction}

The experimental program, presented in this chapter, focuses on the structural behavior of reinforced high strength concrete beams under impact loading. A total of 8 high strength reinforced concrete beams were tested in the Structural Laboratory of Ryerson University, Toronto, Canada. Two of the HS RC beams are tested under monotonic static loading, while the remaining beams are tested under drop-weight impact loading.

This chapter overviews the specimens' details, drop-weight impact test setup, instrumentations, and loading regiments which that have been utilized in this experimental program. The results and discussions are given in the following chapter.

\subsection{Test Specimens}

A total of eight $\mathrm{RC}$ beam specimens with identical cross sections and 2 varying lengths are constructed and tested under drop-weight low-velocity impact loading conditions. All specimen are casted using HSC. Concrete casting and construction of beam formworks are undertaken at the Structural Laboratory of Ryerson University. All beam specimens have a cross sectional height of $600 \mathrm{~mm}$, with a width of $300 \mathrm{~mm}$. Half of the specimens have a length of $3900 \mathrm{~mm}$ while the other half are $5100 \mathrm{~mm}$ long. Test specimens have different parameters and objectives, which are detailed and presented separately in the following sub-sections. 


\subsubsection{Details of Specimens}

Typical bar sizes of 20M, 25M, and 35M are longitudinal reinforcements, while $10 \mathrm{M}$ bars are used for shear stirrups and compression reinforcements at the top. All of the reinforcing bars are CSA standard Grade 400 deformed steel bars [25]. Dimensions of specimens and reinforcement details are shown in Figure 3.1

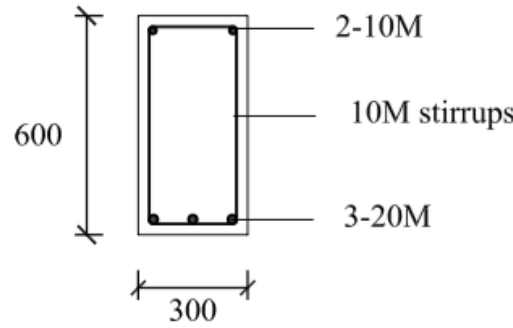

Section A

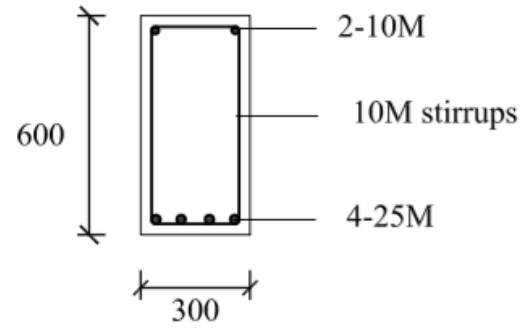

Section B

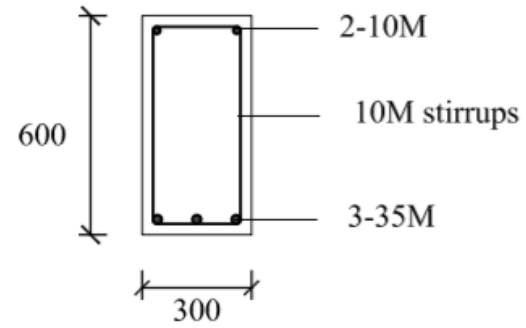

Section C

Figure 3.1 - Details of RC specimens (dimensions in $\mathrm{mm}$ )

Failure mode of HS RC beam specimens under midpoint static loading conditions depends on the range of their bending-shear capacity ratios. Static flexural capacity $\mathrm{P}_{\mathrm{us}}$, and punching-shear capacity $\mathrm{V}_{\text {us }}$ are calculated following the Canadian code CSA A23.3. Details of each specimen's reinforcement, static bending and shear capacities are given in Table 3.1 and the calculations are documented in Appendix A. 
Table 3.1 - Steel reinforcement details and static capacities of HSC specimens

\begin{tabular}{|c|c|c|c|c|c|c|c|}
\hline \multirow{2}{*}{ Beam's ID } & \multicolumn{2}{|c|}{ Bottom Reinforcement } & \multicolumn{2}{c|}{ Top Reinforcement } & \multicolumn{3}{c|}{ Static capacities } \\
\cline { 2 - 8 } & Dai./spacing (mm) & Ratio (\%) & Dai./spacing (mm) & Ratio (\%) & $\mathrm{P}_{\text {us }}(\mathrm{kN})$ & $\mathrm{V}_{\text {us }}(\mathrm{kN})$ & $\mathrm{P}_{\text {us }} / \mathrm{V}_{\text {us }}$ \\
\hline S-3.9-B & $25 / 40$ & 1.19 & $10 / 200$ & 0.119 & 402.57 & 479.16 & 0.84 \\
\hline D-3.9-A & $20 / 80$ & 0.53 & $10 / 200$ & 0.119 & 185.33 & 479.16 & 0.387 \\
\hline D-3.9-B & $25 / 40$ & 1.19 & $10 / 200$ & 0.119 & 402.57 & 479.16 & 0.84 \\
\hline D-3.9-C & $35 / 57.5$ & 1.78 & $10 / 200$ & 0.119 & 588.18 & 479.16 & 1.227 \\
\hline S-5.1-B & $25 / 40$ & 1.19 & $10 / 200$ & 0.119 & 301.929 & 479.16 & 0.597 \\
\hline D-5.1-A & $20 / 80$ & 0.53 & $10 / 200$ & 0.119 & 139 & 479.16 & 0.29 \\
\hline D-5.1-B & $25 / 40$ & 1.19 & $10 / 200$ & 0.119 & 301.929 & 479.16 & 0.63 \\
\hline D-5.1-C & $35 / 57.5$ & 1.78 & $10 / 200$ & 0.119 & 441.14 & 479.16 & 0.92 \\
\hline
\end{tabular}

In order to avoid the formation of cold-joints and to maintain identical concrete properties, all specimens are cast at once using identical concrete batch. Specimens are also cured after casting, by placing a moist burlap and plastic over them a period of seven days. Subsequently, the specimens are taken out of their formwork and left to be dried in laboratory air conditions until target age of 38 days, which testing commence. Construction and casting of eight HSC beam specimens are presented in Figure 3.2.

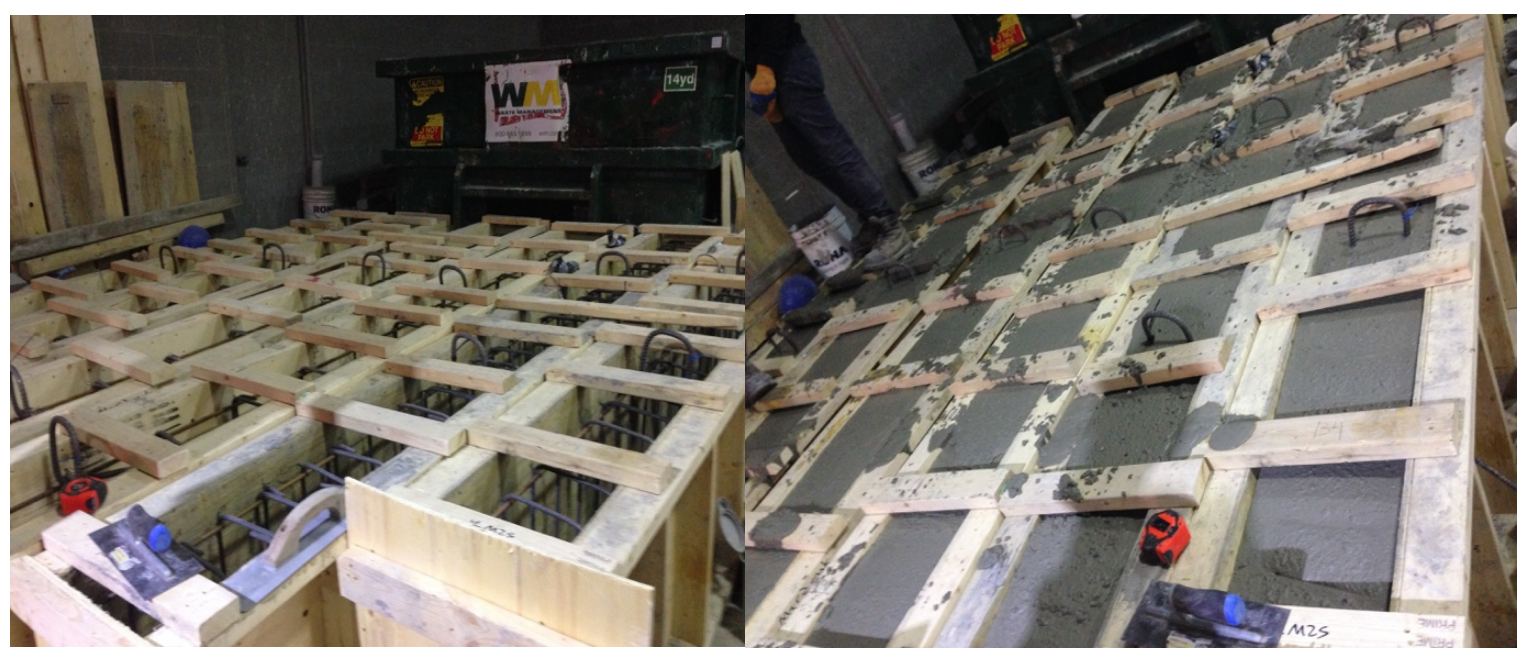

Figure 3.2 - Manufacturing and casting of HSC specimens series 


\subsubsection{Details of HS-RC series}

Eight reinforced concrete beams with identical dimensions and two varying lengths are constructed and six are tested under drop-weight impact load and remaining two under static load as control specimen. The beams are $600 \mathrm{~mm}$ high with a width of $300 \mathrm{~mm}$, with four beams having a length of $3.9 \mathrm{~m}$ and the remaining four a length of $5.1 \mathrm{~m}$. All beams are doubly reinforced with equal top and varying bottom longitudinal steel reinforcements. 10M CSA standard deformed steel bars of Grade 400 [1] are used as top longitudinal and stirrup reinforcement in all beams. Two parameters are considered in the current investigation, namely: bottom longitudinal reinforcement ratio $(0.53$, 1.19 and $1.78 \%$ ) and shear span to depth ratio $(\mathrm{a} / \mathrm{d})$. Beams' formwork construction, rebar preparation and casting are shown in Figure 3.3.

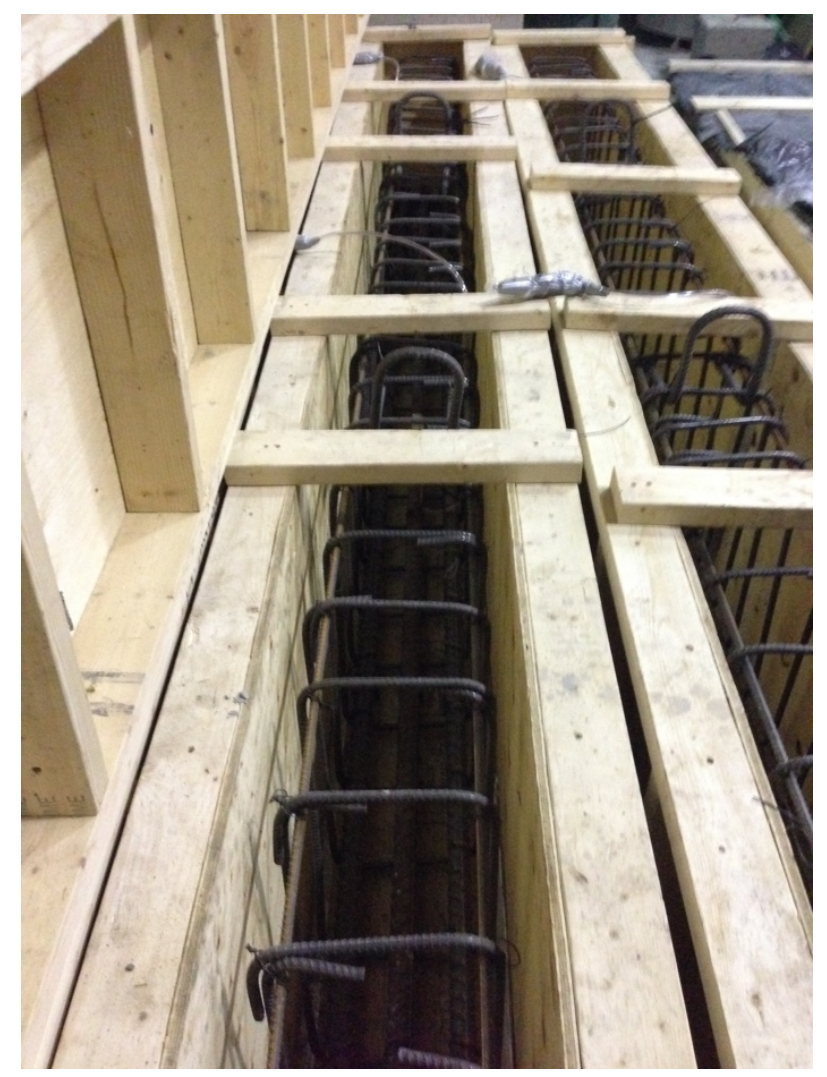

Figure 3.3.a - Manufacturing of HS-RC test beams - Formwork \& rebar preparation 


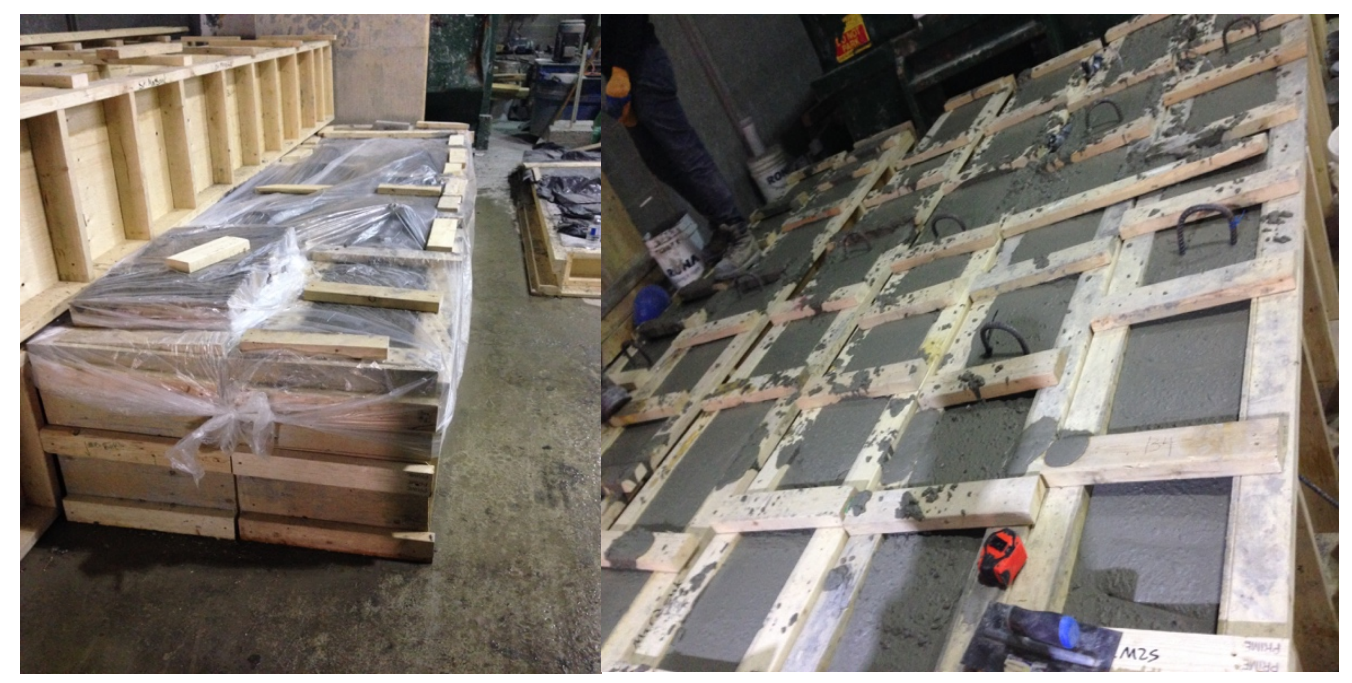

Figure 3.3.b - Manufacturing of HS-RC test beams - Casting of HS-RC beam specimens

\subsection{Drop-weight Impact Testing Setup}

The drop-weight impact setup was designed by Dr. Hesham Othman, a PhD graduate of the Civil Engineering Department of Ryerson University. The setup and the test configuration are illustrated in Figure 3.4 by photos and a schematic diagram. The production and design of the drop-weight low-velocity impact setup has been undertaken at the structural laboratory of Ryerson University. The impact setup has a capacity of $19.30 \mathrm{~kJ}$. The impact setup works by elevating the drop-weight to a desired height above specimens by an electromagnetic hoist, which then the mass is released to impose a hard impact on the specimen. The velocity of the impacting mass is dependent on the height at which the mass is released. [26]

The impact setup consists of three subsystems such as: drop-weight impact frame; supporting system; and instrumentation. Details of subsystems are discussed in the following sub-sections. More specific details are available elsewhere. [27] 


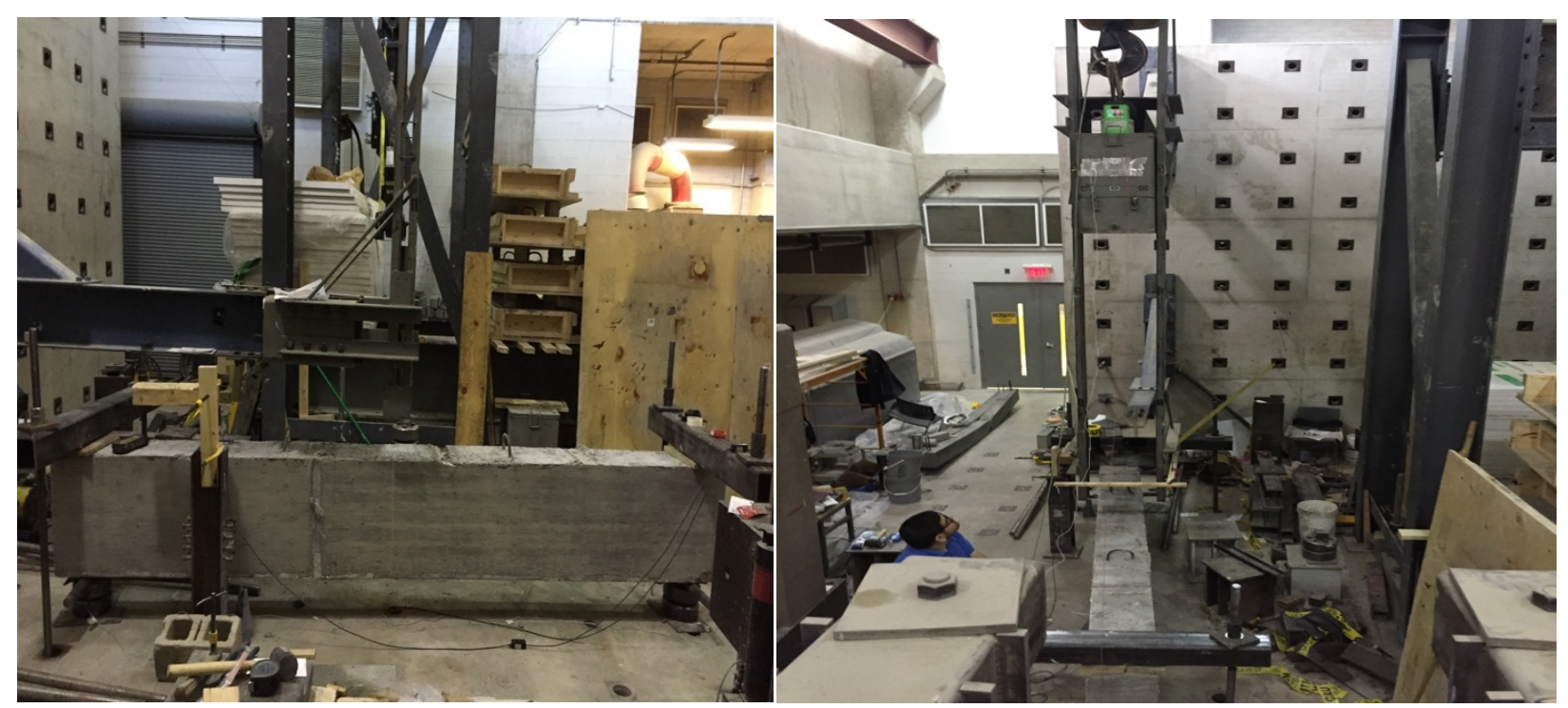

Figure 3.4.a - Setup and impact test configuration

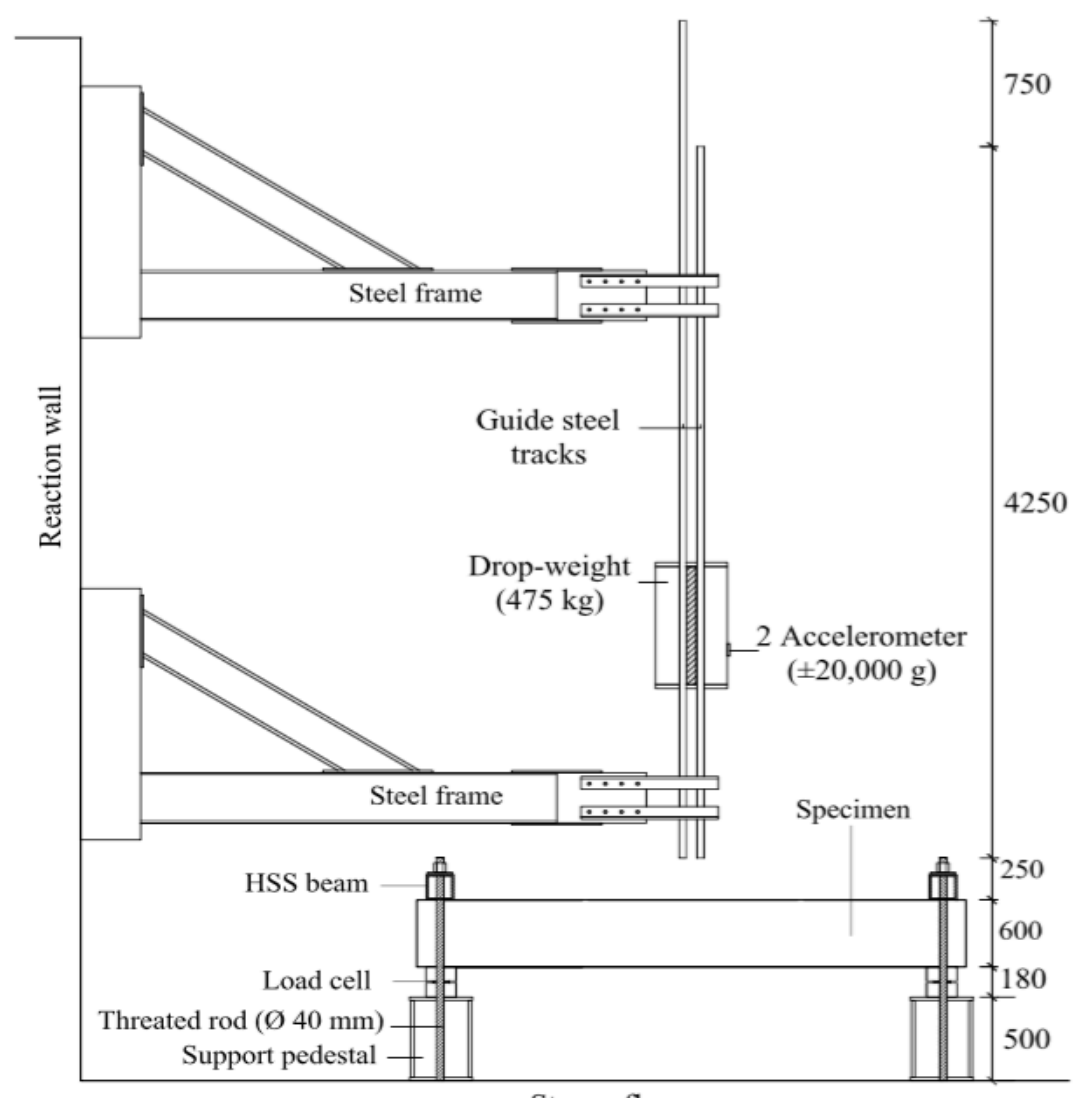

Strong floor

Figure 3.4.b - Schematic diagram of impact test setup 


\subsubsection{Drop-weight impact frame}

The frame of the drop-weight impact setup, has a capacity of dropping a $475 \mathrm{~kg}$ mass from a maximum height of $4.15 \mathrm{~m}$. A tower frame with vertical steel tracks is utilized to guide the dropweight mass. Therefore, it is possible to ensure the accuracy of impact location on the specimens and avoid damages to the instrumentation during the impact test. The frame of the impact setup is connected to a $1 \mathrm{~m}$-thick concrete reaction wall. (Figure 3.4).

\subsubsection{Supporting system}

The HS RC beam specimens are simply supported at both ends. End supports are selected in order to reduce the measurements of reaction forces to specific points such as end points. Each of the end supports are tied down using a special tie down frame which consists of a hollow structural section (HSS) and is anchored at both ends to the concrete floor of the laboratory by two $40 \mathrm{~mm}$ diameter, high-strength threaded steel rods. The arrangement of the supporting system shown with detail in Figure 3.5.

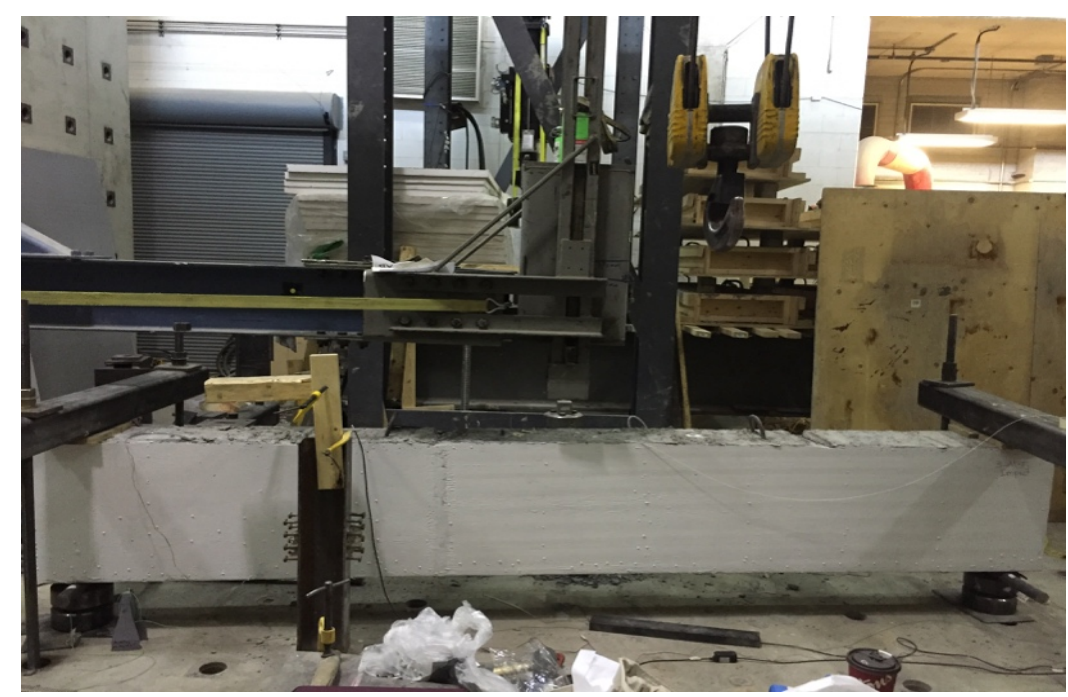

Figure 3.5.a - End supports arrangements of the beam specimen under testing 


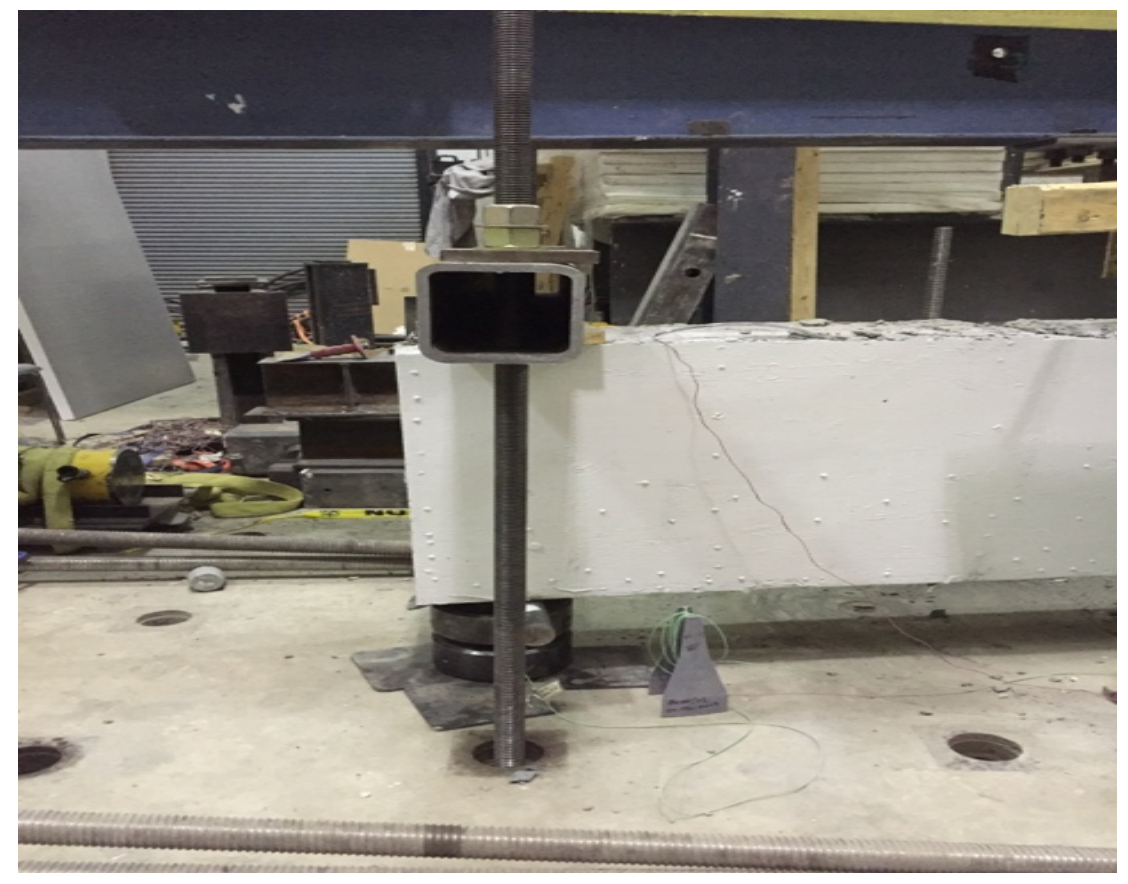

Figure 3.5.b - End support system details

\subsection{Instrumentation}

The impact test setup is equipped with sophisticated instrumentation which monitors applied and reaction forces, specimen deflections, and stains of steel reinforcing bars. The instrumentations are discussed in the following sub-sections.

\subsubsection{Accelerometers}

Two accelerometers are used to measure the acceleration of the falling drop-weight. Therefore, the impact force developed by the falling drop-weight can be determined based on Newton's $2^{\text {nd }}$ law. These instruments are mounted onto the falling drop weight. The utilized accelerometers are manufactured by Kistler Instrument Corporation (Model: 8742A20) and have a maximum capacity 
range of $\pm 20,000 \mathrm{~g}$, where $\mathrm{g}$ is the gravitational acceleration of earth). The accelerometers are calibrated by the manufacturing company.

\subsubsection{Quartz dynamic load cells}

The quartz load cells are used to determine the reaction forces between the supports and specimen which is induced by the applied impact load. The load cells consist of a quartz force sensor and is positioned between two thick steel caps in order to protect the electrical connectors during the test procedure. The quartz force sensors are also a product of Kistler Instrument Corporation (Model: 9107A). Each individual quartz load cell has a capacity of $650 \mathrm{kN}$. The mentioned quartz force sensors have significant capabilities in measuring dynamic force and quasi-static forces in comparison with strain gauge type sensors. Quartz force sensors are small and stiff which provide high frequency response resulting in accurate capture of data for short-duration impulse force. The stiffness of the quartz sensor structure, provides an extremely fast rise time which enables accurate capture of events caused by rapid force transients. However, the use of quartz force sensors in static or long-term loading testing is not practical, due to time dependent decay of the measurement signals generated by a quartz force sensor.

\subsubsection{Strain gauges}

The magnitude and rate of strain in the steel reinforcements are measured by strain gauges. The used strain gauges have a $5 \mathrm{~mm}$ gauge length and are a product of Tokyo Sokki Kenkyujo Co. Ltd. (Model: TML FLA-5-11). One strain gauge is glued to the surface of the longitudinal reinforcement at the midpoint of each beam specimen. One strain gauge is also glued to the mid height surface of the shear stirrup reinforcement, which is located at the maximum shear point of 
the beam specimen $(\mathrm{d} / 2)$. The steel reinforcement surfaces at which the strain gauge sensor are placed, are slightly grinded and cleaned by alkaline and acidic chemicals. Strain gages are then fixed to the steel surface by a glue which is provided by the manufacturer. Afterwards, the strain gauges are covered by a protective layer of paraffin wax covered by aluminum tape to minimize the possible damage imposed during concrete casting. Figure 3.6 shows the attached strain gauge to the steel surface.

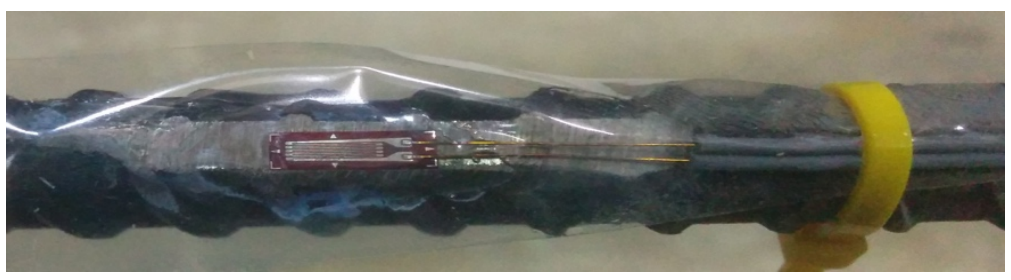

Figure 3.6 - Installed strain gauge on steel reinforcement

\subsubsection{Displacement laser sensor}

Contact-less laser sensors are utilized to measure displacements of the beam specimen upon application of external loading. The traditional displacement gauge sensors (e.g. Potentiometer and LVDT) are physically connected to the impacted specimen and due to possible physical damage, they are highly susceptible to displacement data loss, according to majority of previous impact test investigations. The contact-less laser sensor has no physical connection to the specimen what so ever. This way the risk of displacement data loss is significantly mitigated. The used contact-less laser sensors are manufactured by KEYENCE (Model: IL-300), which features a semi-conductor laser with a wavelength of $655 \mathrm{~nm}$ with a measuring range of 160-450 $\mathrm{mm}$. [41] Two laser displacement sensors are utilized for each beam specimen, one positioned at midpoint of the beam length another at the one-quarter point of the specimen length. The laser sensors positioned at middle and quarter points are demonstrated in Figure 3.7. 


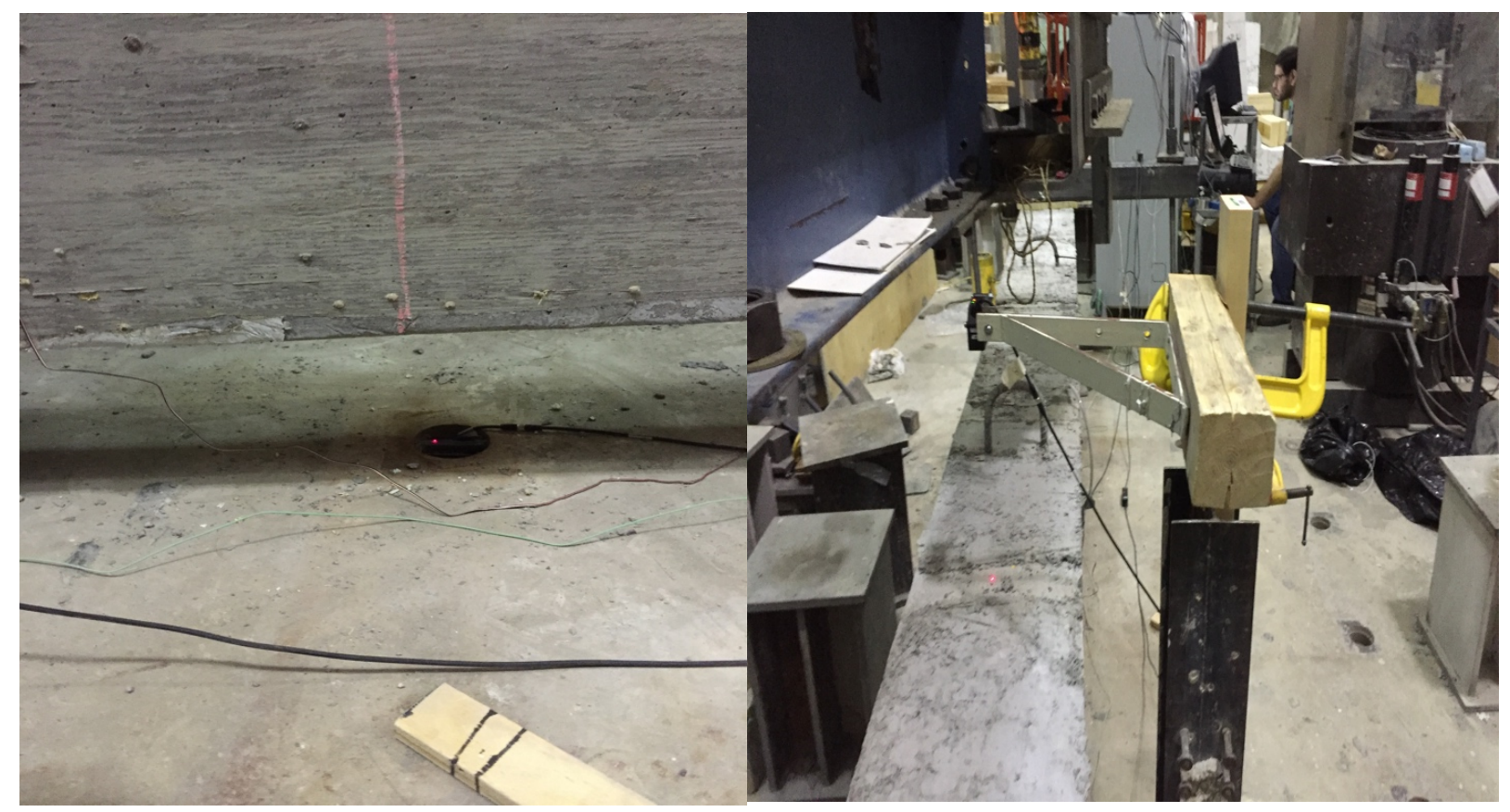

Figure 3.7 -Laser displacement sensors placement

\subsubsection{Data acquisition system}

A digital dynamic data acquisition system manufactured by ECON (Model: MI-7008) is utilized to record the raw experimental data. The data acquisition system features IEPE sensors with a sampling rate of $300 \mathrm{MHz}$. These sensors have the capability of capturing data, playback, shock recording, analysis and software processing. In this experimental program, the reaction and acceleration data are more probable to contain large amplitude and high frequency content. Therefore, a sampling rate of $100 \mathrm{kHz}$ is adopted by the IEPE sensors for recording the data from accelerometers and load cells. However, a sampling rate of $5 \mathrm{kHz}$ is adopted for displacement and strain data since they exhibit a lower frequency content by nature. An important note to mention at last, is that these sampling rates are preferred according to previous research on numerical simulations [28] of HSC plates undertaken by Murtiadi and Marzouk (2001) [29]. 


\subsubsection{Loading Protocol and Test Termination}

Two of the beams with identical reinforcement ratio (1.19\%) and various spans $(3.9 \mathrm{~m} \& 5.1 \mathrm{~m})$ were tested under static loading in order to establish a reference behavior of the beams. The statically tested beams were loaded by increments of $15 \mathrm{kN}$, until ultimate failure of the beams occurred and at which load increase was no longer possible. Six of the beams with various reinforcement ratio and spans were tested dynamically. All dynamic test specimens were subjected to 3 impact using the drop-weight impact test setup. The impacting mass is released at a height of $4.15 \mathrm{~m}$ for every drop of the impact test. 


\section{CHAPTER 4}

\section{RESULTS AND DISCUSSIONS}

\subsection{Introduction}

Two series of tests with varying loading rates are conducted on RC beams. The details of the two test series including the developed static and drop-weight impact setup and relative implemented instrumentation are provided in the previous chapter. The mechanical properties of the concrete and reinforcing steel used in construction of beam specimens are tested and reported. At last, the results and discussion are presented in two separate sections according to loading rate. Additionally, only selected results are presented to characterize the influence of studied parameters on the impact response and failure pattern of tested beams.

\subsection{Materials Mechanical Properties}

\subsubsection{High-strength concrete properties}

The tested mechanical properties and characteristics are summarized in Table 4.1. Each data point in the table is averaged from three tested specimens. Compression and splitting tensile tests are conducted on cylinders with dimensions of $100 \times 200 \mathrm{~mm}$. Compressive tests are conducted according to ASTM C39 with a loading rate of $0.36 \mathrm{~mm} / \mathrm{min}$ and the strain is captured according to ASTM C469. Splitting tensile tests are conducted according to ASTM C496 with a loading rate of $0.05 \mathrm{~mm} / \mathrm{min}$. On the other hand, three-point flexural strength tests are conducted on $100 \times 100 \times 400 \mathrm{~mm}$ prisms with a clear span of $300 \mathrm{~mm}$ and a loading rate of $0.18 \mathrm{~mm} / \mathrm{min}$. In addition to tested properties, mass density of the material is measured by taking the average mass of three cylinders. 
Table 4.1 Characteristic mechanical properties of HSC

\begin{tabular}{|c|c|}
\hline Compressive strength $\left(\mathrm{f}_{\mathrm{c}}{ }^{\prime}\right)$ & $72.50 \mathrm{MPa}$ \\
\hline Elastic modulus $\left(\mathrm{E}_{\mathrm{c}}\right)$ & $31.20 \mathrm{GPa}$ \\
\hline Flexural strength $\left(\mathrm{f}_{\mathrm{r}}\right)$ & $6.92 \mathrm{MPa}$ \\
\hline Splitting tensile strength $\left(\mathrm{f}_{\mathrm{spt}}\right)$ & $4.75 \mathrm{MPa}$ \\
\hline Mass density $(\rho)$ & $2,510 \mathrm{~kg} / \mathrm{m} 3$ \\
\hline
\end{tabular}

The following figure shows the testing procedures, failure patterns, and the response of conducted mechanical property tests. It should be mentioned that HSC exhibits an explosive failure under compression test and a sudden brittle failure under flexural and tensile splitting tests. HSC reached its compressive strength at a strain of $2.40 \%$.
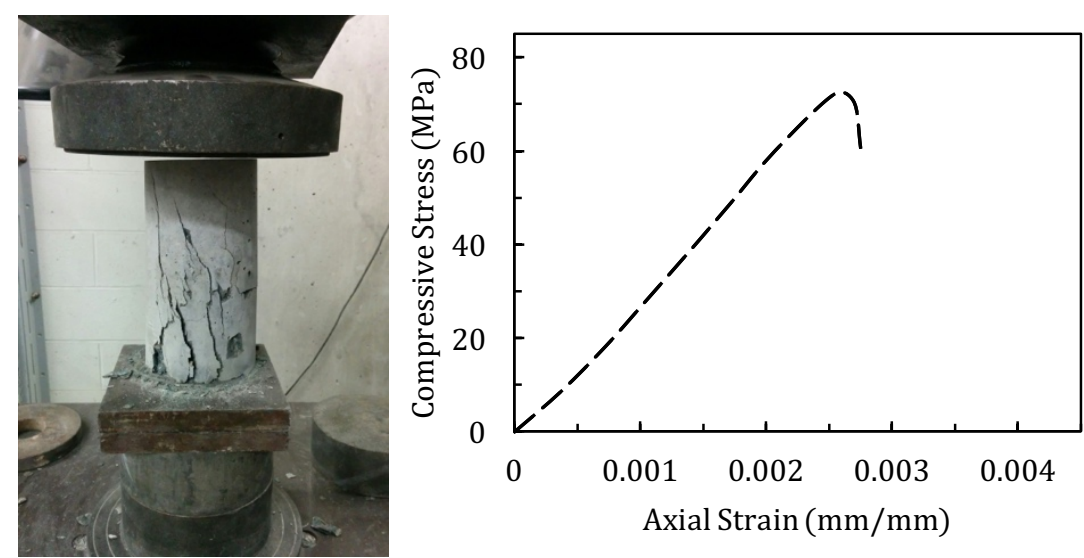

a) Compressive strength test
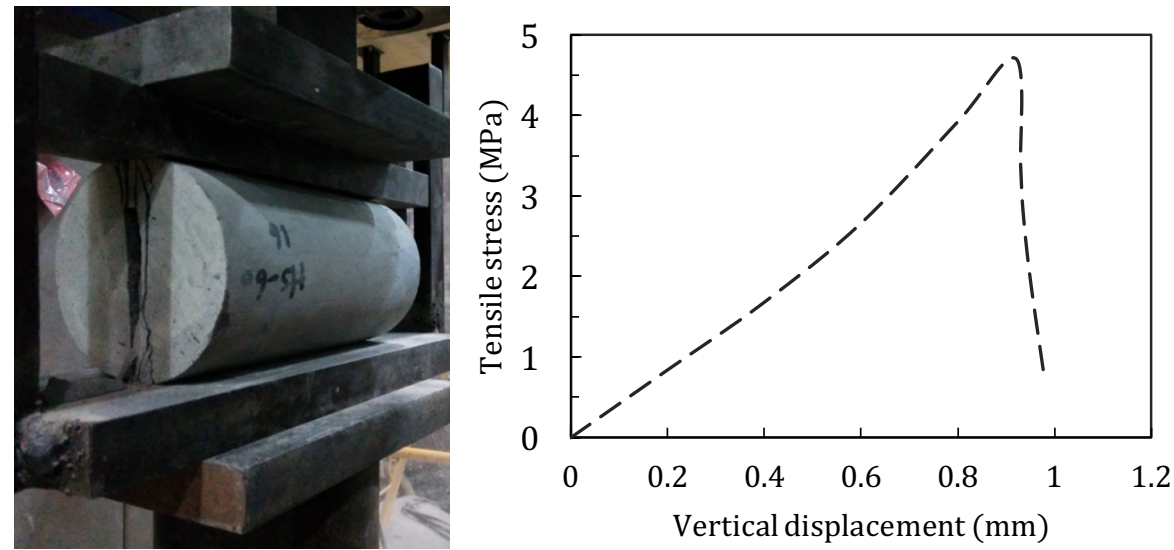

b) Tensile splitting test 

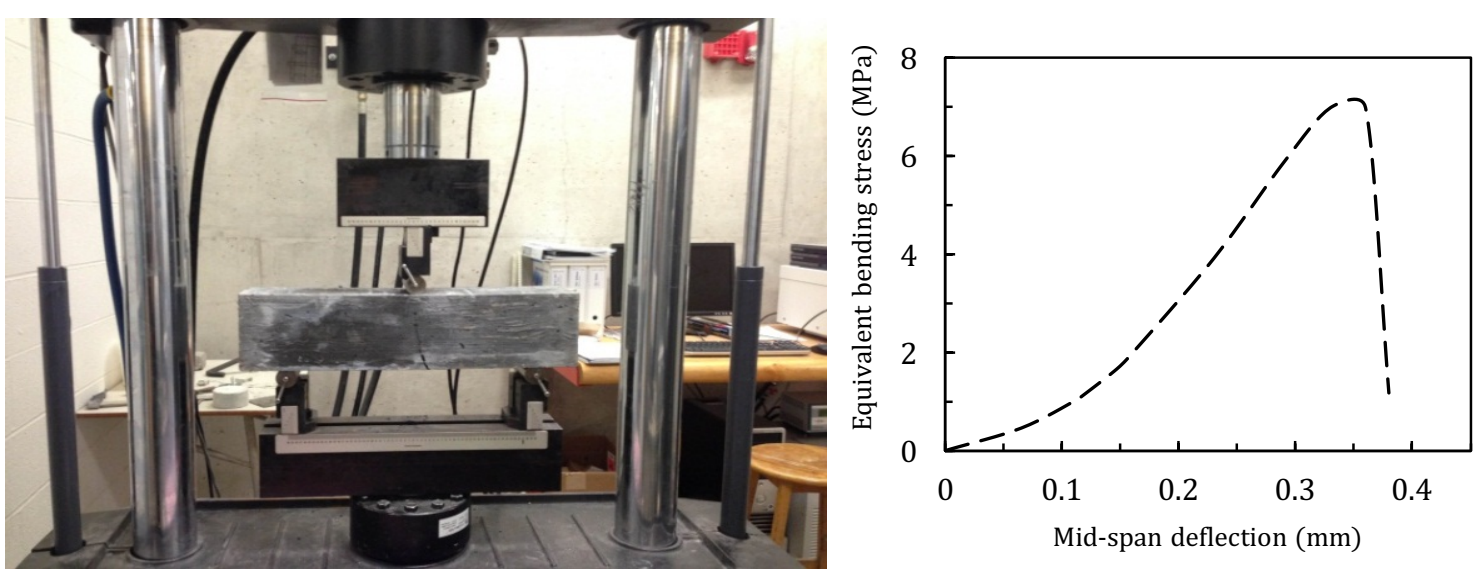

c) Three-point bending test

Figure 4.1- Characteristic mechanical properties of HSC

\subsubsection{Steel reinforcement properties}

As previously mentioned in Chapter 3, CSA standard Grade 400 deformed steel bars are used as longitudinal reinforcement and stirrups in the RC beam specimens. Four typical bar sizes of 10M, 20M, $25 \mathrm{M}$ and $35 \mathrm{M}$ are used. The tested geometrical and mechanical properties of steel reinforcements are summarized in Table 4.2. Each data in the table is averaged from three test readings. Tensile coupon tests are carried out to determine the mechanical properties of steel reinforcement bars (Figure 4.2). The density is determined by measuring the weight of a meter-long steel bar.

Table 4.2 Characteristics properties of steel reinforcement

\begin{tabular}{|c|c|c|c|c|c|}
\hline $\begin{array}{c}\text { Steel bar } \\
\text { size }\end{array}$ & $\begin{array}{c}\text { Diameter } \\
(\mathrm{mm})\end{array}$ & $\begin{array}{c}\text { Mass } \\
(\mathrm{kg} / \mathrm{m})\end{array}$ & $\begin{array}{c}\text { Yield stress } \\
\mathrm{f}_{\mathrm{y}},(\mathrm{MPa})\end{array}$ & $\begin{array}{c}\text { Ultimate } \\
\text { strength } \mathrm{f}_{\text {ult, }}, \\
(\mathrm{MPa})\end{array}$ & $\begin{array}{c}\text { Elastic } \\
\text { modulus } \mathrm{E}_{\mathrm{s}}, \\
(\mathrm{GPa})\end{array}$ \\
\hline $10 \mathrm{M}$ & 11.29 & 0.775 & 433.4 & 621.70 & 201.1 \\
\hline $20 \mathrm{M}$ & 19.53 & 2.345 & 451.20 & 629.10 & 198.60 \\
\hline $25 \mathrm{M}$ & 25.21 & 3.920 & 458.80 & 631.25 & 200.90 \\
\hline $35 \mathrm{M}$ & 35.70 & 7.849 & 445.50 & 625.30 & 202.24 \\
\hline
\end{tabular}



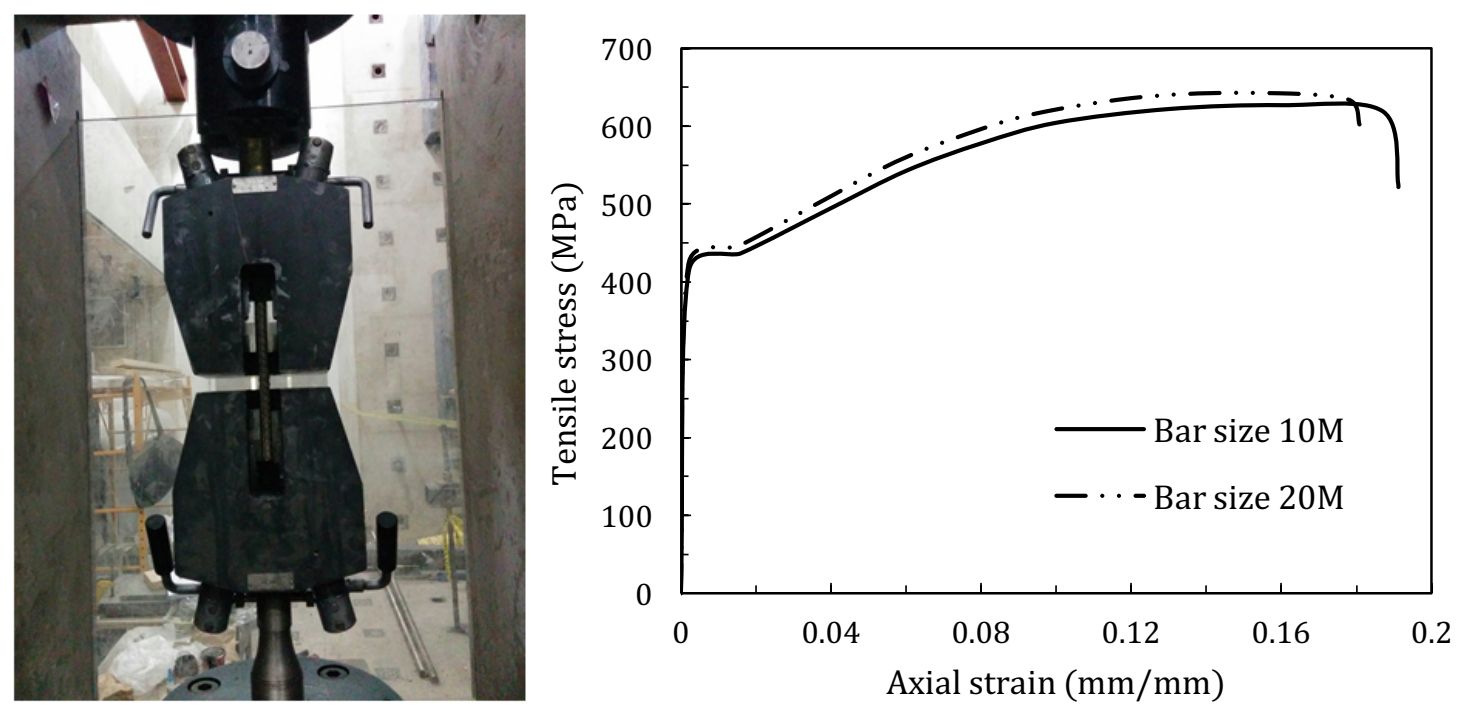

Figure 4.2 - Steel reinforcement coupon testing

\subsection{Static testing results}

\subsubsection{Static testing measurements}

The mid-span load-deflection responses obtained from static tests are presented in Figure 4.3. The applied force is measured using calibrated load cells and mid-span displacement is recorded using LVDT. It should be recalled that both specimens have same concrete cross-section area, steel reinforcement, and concrete material. However, the span length is different. Therefore, the specimen with larger span would exhibit lower flexural loading capacity. It is evident from Figure 4.3 that S-3.9-B specimen has higher loading capacity in comparison with S-5.1-B specimen which translates into higher stiffness, absorbed energy, and displacement capacity. 


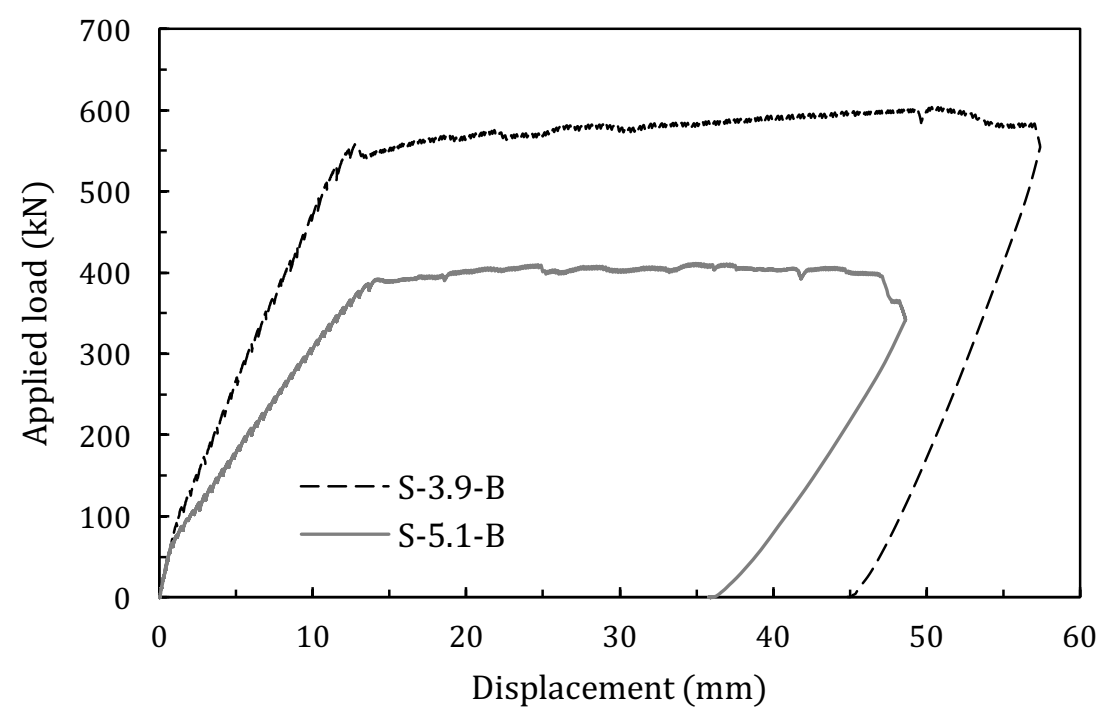

Figure 4.3 - Static midspan load-displacement responses

The following table presents the maximum measured responses during the static tests. As shown in the table, the strain of longitudinal steel reinforcement at mid-span is yielding. Meanwhile the strain of steel stirrups at critical section did not reach the yield strain. Both the mentioned observations confirm that the RC beams failed in flexural mode.

Table 4.3 - Static test measurements

\begin{tabular}{|c|c|c|c|c|c|}
\hline Specimen & Failure mode & Load $(\mathrm{kN})$ & $\begin{array}{c}\text { Midspan } \\
\text { displacement } \\
(\mathrm{mm})\end{array}$ & $\begin{array}{c}\text { Steel strain } \\
\text { midspan }\end{array}$ & $\begin{array}{c}\text { Steel strain } \\
\text { Stirrups }\end{array}$ \\
\hline S-3.9-B & Flexural & 603.7 & 57.4 & 15,545 & 1,412 \\
\hline S-5.1-B & Flexural & 411.6 & 48.7 & 15,604 & 455 \\
\hline
\end{tabular}

\subsubsection{Crack pattern of static test}

Figure 4.4 shows the final crack pattern of the two specimens tested under static loading. Longitudinal steel strain readings suggested that they have reached yield point while the shear stirrups did not reach yield point, confirming that both specimens (S-3.9-B and S-5.1-B) are failed in a flexural mode with the formation of vertical cracks at tensile section of mid-span. Such 
observations are expected since the two specimens are designed to be flexure critical with a flexure to shear load capacity ratio smaller than 1 .

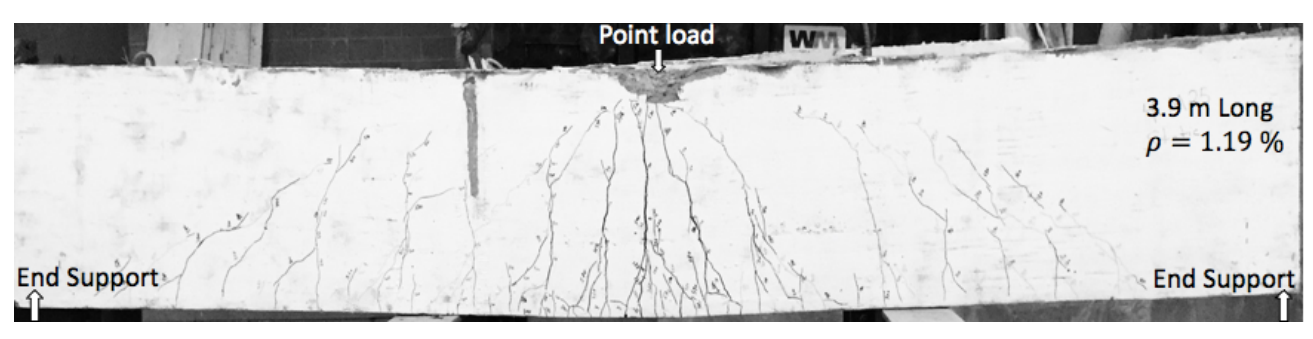

a) S-3.9-B

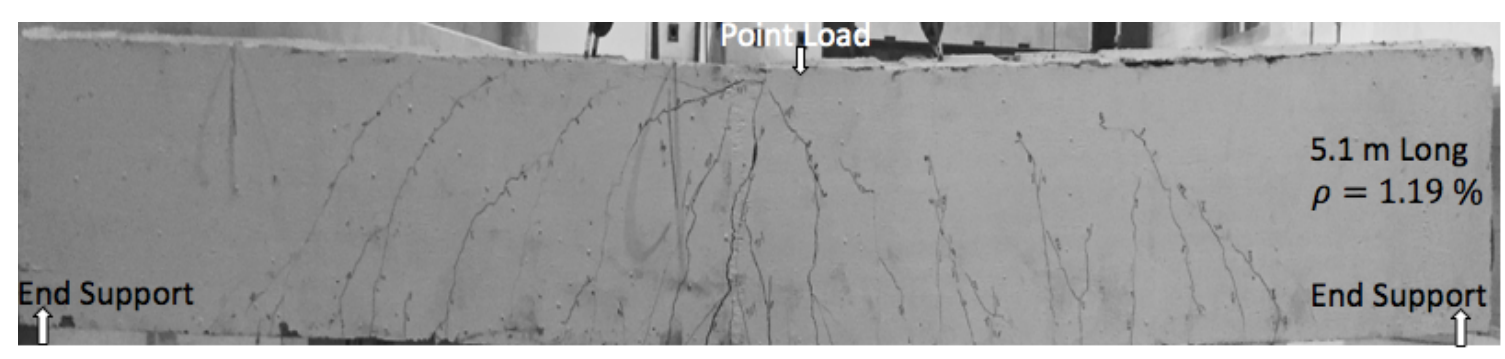

b) S-5.1-B

Figure 4.4 Crack pattern for beams tested under static loading conditions

\subsection{Drop-weight impact testing results}

The drop-weight impact test results and measurements of the tested RC beams are reported and discussed with details in this section. The reported results are focused on impact and reaction force characteristics followed by specimen's response.

\subsubsection{Characteristics of impact and reaction forces}

The impact and total reaction forces-time histories for all beam specimens are found to response in a similar manner as shown in Figure 4.5. The impact force excited by the falling steel weight is determined by Newton's $2^{\text {nd }}$ law using the acceleration data recordings of drop-weight. The shown reaction is the total reaction force determined by summing the measurements of the two load cells 
since the reaction force responses from load cells are similar in terms of magnitude and time response.

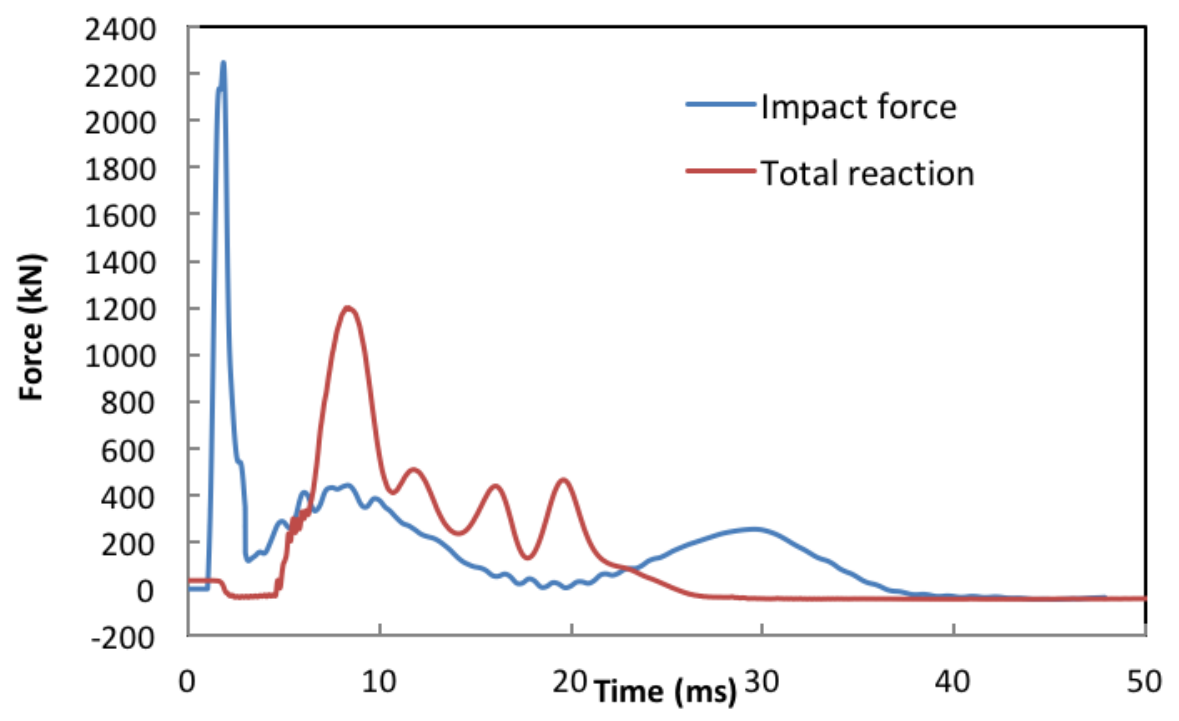

a) D-3.9-A

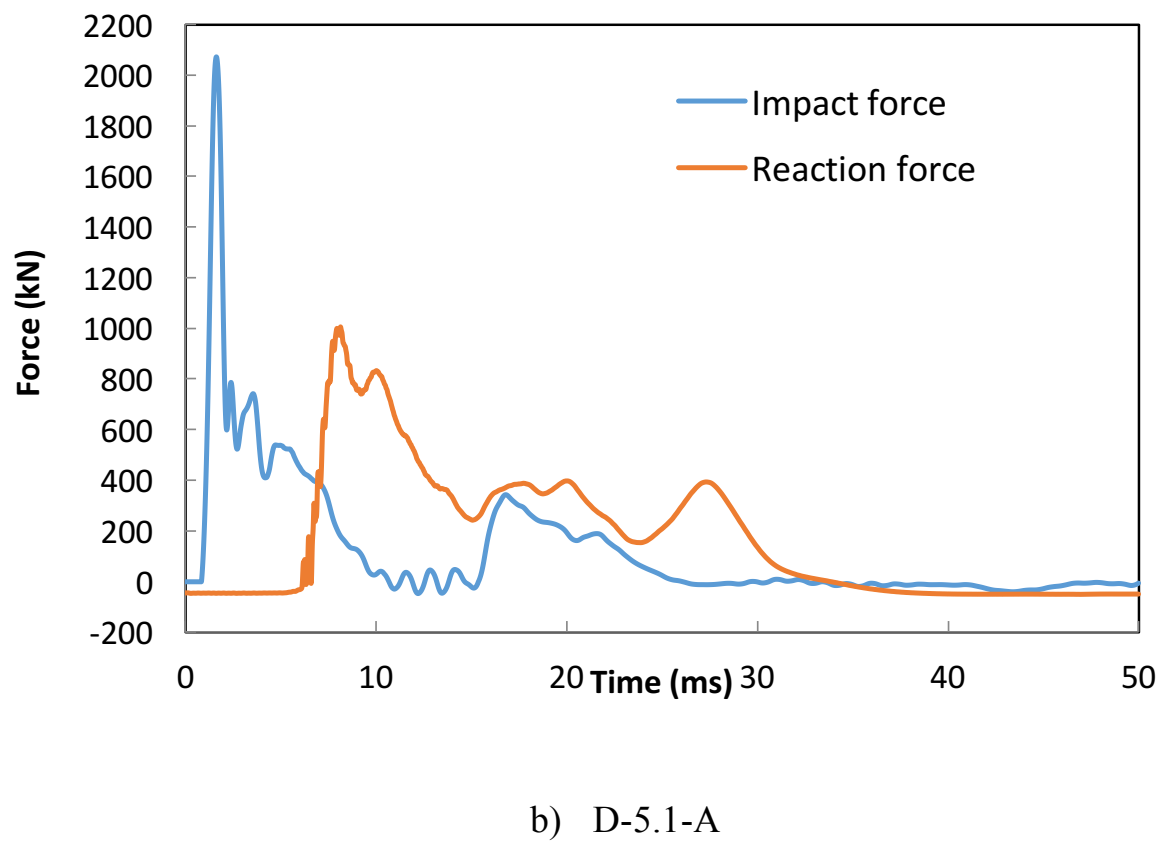

Figure 4.5 Impact and reaction forces-time histories 
By comparison of the impact force to the reaction force, it is evident that peak amplitude of the impact force is greater than that of the reaction force, the reason being that most of impact force is used to balance the inertia force or accelerate the beam, while only a small portion of impact force contributes in deforming and fracturing the specimens. There is also a time lag between the maximum impact force and the maximum reaction force, which is due to the stress wave propagation traveling from the impact zone to the supports. These observations can be also found in References [33-35]. The following table presents the peak impact and reaction forces with the corresponding time of each response.

Table 4.4 - Peak Impact and reaction forces

\begin{tabular}{|c|c|c|c|c|c|}
\hline Impact test & $\begin{array}{l}\text { Test } \\
\text { No. }\end{array}$ & \multicolumn{2}{|c|}{ Impact force } & \multicolumn{2}{c|}{ Total reaction force } \\
\cline { 3 - 6 } & & Peak $(\mathrm{kN})$ & Time $(\mathrm{ms})$ & Peak $(\mathrm{kN})$ & Time $(\mathrm{ms})$ \\
\hline $\mathrm{D}-3.9-\mathrm{A}$ & 1 & 2253.25 & 1.6 & 1199.31 & 8.35 \\
\cline { 2 - 6 }$\left(900 \mathrm{~mm}^{2}\right)$ & 2 & 2244.80 & 2.52 & 1152.84 & 8.70 \\
\cline { 2 - 6 } & 3 & 2080.05 & 2.76 & 959.12 & 8.09 \\
\hline $\mathrm{D}-3.9-\mathrm{B}$ & 1 & 2421.195 & 1.50 & 1238.32 & 8.10 \\
\cline { 2 - 6 }$\left(2000 \mathrm{~mm}^{2}\right)$ & 2 & 2749.91 & 3.43 & 1221.87 & 8.18 \\
\cline { 2 - 6 } & 3 & 28386.46 & 2.51 & 1189.95 & 9.10 \\
\hline D-3.9-C & 1 & 2623.15 & 1.75 & 1385.8 & 7.35 \\
\cline { 2 - 6 }$\left(3000 \mathrm{~mm}^{2}\right)$ & 2 & 2439.50 & 1.97 & NA & NA \\
\cline { 2 - 6 } & 3 & 19421.02 & 5.95 & 1251.33 & 8.96 \\
\hline D-5.1-A & 1 & 2127.835 & 1.40 & 994.3 & 11.15 \\
\cline { 2 - 6 }$\left(900 \mathrm{~mm}^{2}\right)$ & 2 & 2148.475 & 3.20 & 935.72 & 13.36 \\
\cline { 2 - 6 } & 3 & 2126.34 & 1.68 & 902.4 & 15.16 \\
\hline D-5.1-B & 1 & 2250.85 & 1.05 & 1280.44 & 8.35 \\
\cline { 2 - 6 }$\left(2000 \mathrm{~mm}^{2}\right)$ & 2 & 2289.72 & 1.30 & 1219.24 & 8.49 \\
\cline { 2 - 6 } & 3 & 2249.53 & 1.19 & 927.71 & 11.15 \\
\hline D-5.1-C & 1 & 2350.1 & 1.72 & NA & NA \\
\cline { 2 - 6 }$\left(3000 \mathrm{~mm}^{2}\right)$ & 2 & 2142.97 & 2.40 & 1385.82 & 10.32 \\
\cline { 2 - 6 } & 3 & 2033.525 & 2.36 & 1054.94 & 10.83 \\
\hline
\end{tabular}




\subsubsection{Displacement response}

Figure 4.6 shows typical mid-span and quarter-point displacement time histories for two different specimens. The displacement time history of the second and third impact tests, only account for event measurements and do not include the accumulation of residual values from the previous impact test. Displacements are measured using contact-less laser (Keyence IL-300) sensor.

The displacement-time histories for all specimens responded similarly, as shown. Under each impact, the midpoint exhibited a progressively increasing peak (downward is positive) followed by residual displacements, and the specimen vibrates at the equilibrium position. The beam freely vibrates at zero equilibrium freely while there is no plastic deformation or damage occurred in the beam due to impact. In case the plastic deformation occurs, the beam vibrates at the new equilibrium position known as permanent displacement offset (the position about which the subsequent free vibrations of the nonlinear system occur).

Figure 4.7 presents displacement-time histories for first, second and third impact tests of two different specimens (D-3.9-A and D-5.1-A). Typically, the specimens' displacement exhibited progressively increasing peak followed by residual displacements. The effect of damage level is evident in this comparison; under first impact there slightly is a permanent displacement offset which indicates that only slight deformation took place. However, the displacement histories of second and third impact tests show larger peak. It is also evident from Figure 4.7 that there is natural period under successive impacts. This period elongation resulted from stiffness loss of damaged beams, since natural vibration frequency is proportional to modulus of elasticity and moment of inertia and as these parameters decay by damage caused due to successive impacts, the frequency decreases and natural period elongation occurs. 


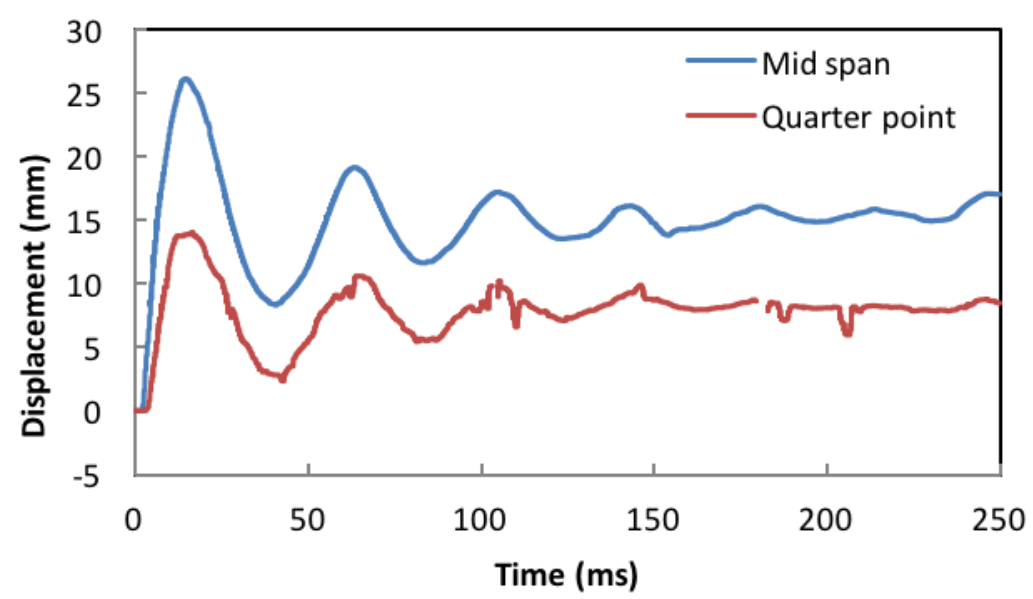

a) D-3.9-A

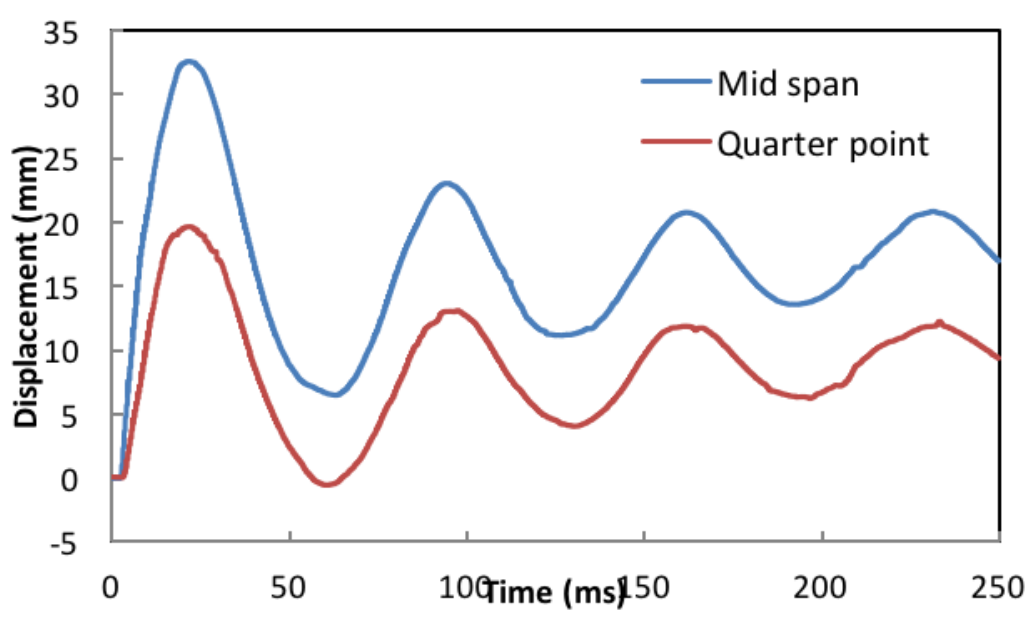

b) D-5.1-A

Figure 4.6 -Displacement-time histories ( $1^{\text {st }}$ Impact) 


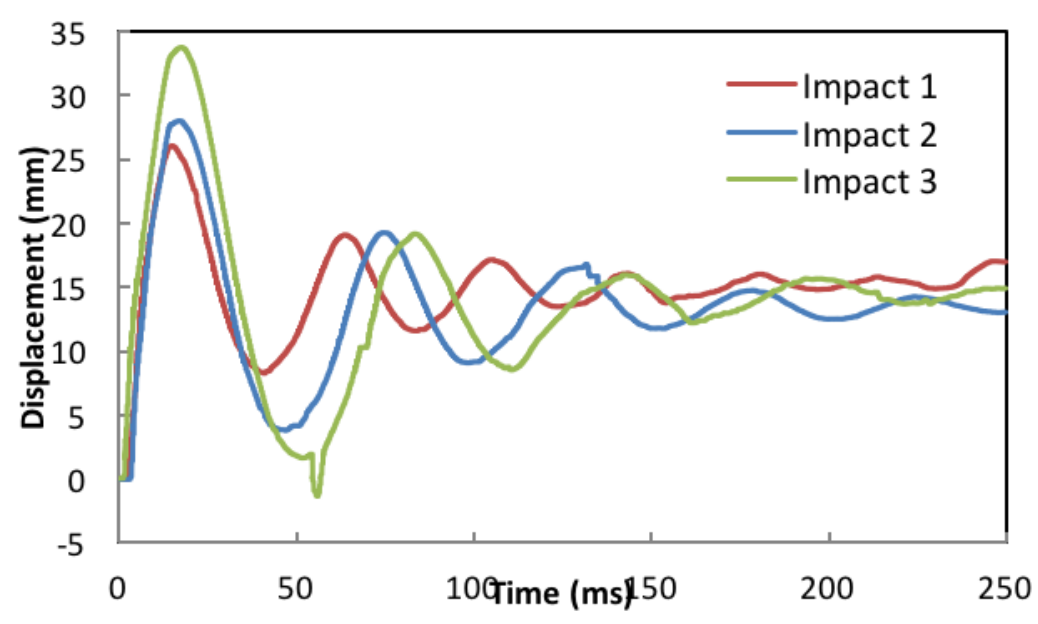

a) D-3.9-A

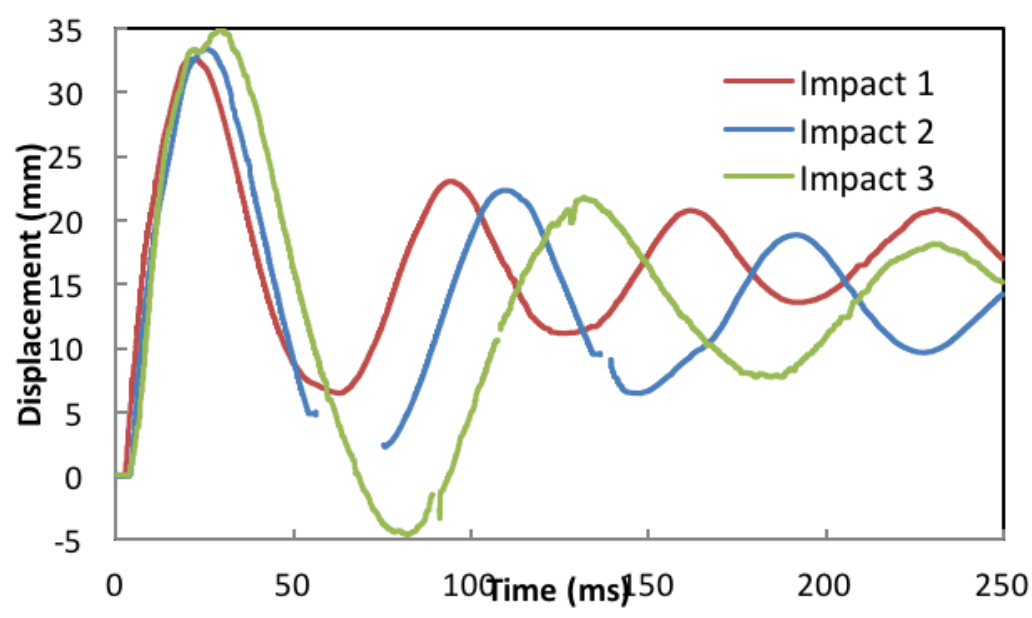

b) D-5.1-A

Figure 4.7 - Mid span displacement-time histories at different damage levels

The effect of main steel reinforcement ratio is shown in Figure 4.8. Main reinforcement ratio plays an important role in limit peak displacement and residual displacement. Beams with longitudinal reinforcement ratio of $0.5 \%$ demonstrated a higher deflection capacity by up to $46 \%$ compared to beams with longitudinal reinforcement ratio of $1.2 \%-1.8 \%$. It should be mentioned that all beams in this comparison have same span and concrete cross section area. 


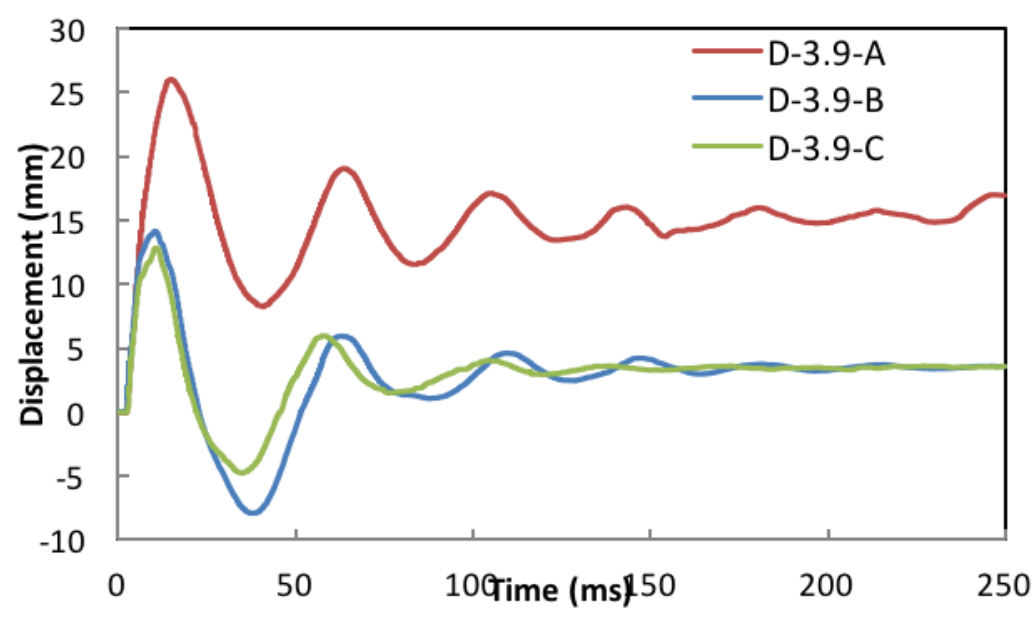

Figure 4.8 - Effect of steel reinforcement ratio on mid span displacement

Figure 4.9 presents the influence of increasing the span on the mid span displacement response. As shown increasing the span resulted in decreasing the stiffness which results in higher peak displacement and elongation in the natural period for beam specimen with $\mathrm{a} / \mathrm{d}=4.28$.

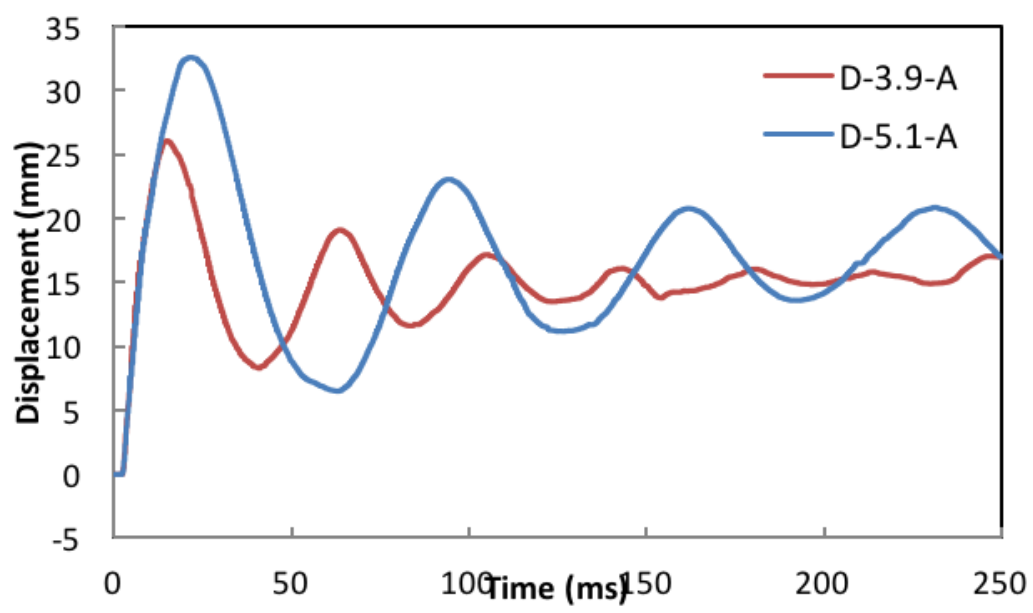

Figure 4.9 - Effect of span on mid span displacement.

A summary of maximum displacements and the corresponding time of both mid span and quarter point are reported in Table 4.5. The residual displacements measured after testing are listed as 
well. It should be pointed out that the reported displacement values represent event measurements and do not include the accumulation of residual values from the previous impact test.

Table 4.5 - Summary of specimens displacement

\begin{tabular}{|c|c|c|c|c|c|c|c|}
\hline \multirow[t]{2}{*}{ Specimen } & \multirow{2}{*}{$\begin{array}{l}\text { Test } \\
\text { No. }\end{array}$} & \multicolumn{3}{|c|}{ Mid span displacement } & \multicolumn{3}{|c|}{ Quarter point displacement } \\
\hline & & $\begin{array}{l}\text { Peak } \\
(\mathrm{mm})\end{array}$ & $\begin{array}{l}\text { Time } \\
(\mathrm{ms})\end{array}$ & $\begin{array}{l}\text { Residual } \\
\text { (mm) }\end{array}$ & $\begin{array}{l}\text { Peak } \\
(\mathrm{mm})\end{array}$ & $\begin{array}{l}\text { Time } \\
(\mathrm{ms})\end{array}$ & $\begin{array}{l}\text { Residual } \\
\text { (mm) }\end{array}$ \\
\hline \multirow{3}{*}{$\begin{array}{c}\text { D-3.9-A } \\
\left(900 \mathrm{~mm}^{2}\right)\end{array}$} & 1 & 26.075 & 15.15 & 15.7 & 13.99 & 16.9 & 7.9 \\
\hline & 2 & 28.06 & 16.92 & 14.3 & 13.1 & 17.9 & 5.1 \\
\hline & 3 & 33.72 & 17.5 & 15.2 & 15.32 & 17.1 & 5.8 \\
\hline \multirow{3}{*}{$\begin{array}{c}\text { D-3.9-B } \\
\left(2000 \mathrm{~mm}^{2}\right)\end{array}$} & 1 & 14.13 & 10.47 & 5.1 & 10.48 & 10.76 & 3.3 \\
\hline & 2 & 16.25 & 12.12 & 2.7 & 11.85 & 12.8 & 1.6 \\
\hline & 3 & 19.35 & 12.4 & 0.7 & 12.15 & 12.64 & 0.3 \\
\hline \multirow{3}{*}{$\begin{array}{c}\text { D-3.9-C } \\
\left(3000 \mathrm{~mm}^{2}\right)\end{array}$} & 1 & 12.85 & 10.71 & 3.8 & 8.2 & 10.75 & 3.4 \\
\hline & 2 & 13.79 & 9.85 & 2.5 & 9.34 & 8.84 & 1.6 \\
\hline & 3 & 16.05 & 12.02 & 0.7 & 10.78 & 13.54 & 0.25 \\
\hline \multirow{3}{*}{$\begin{array}{c}\text { D-5.1-A } \\
\left(900 \mathrm{~mm}^{2}\right)\end{array}$} & 1 & 32.54 & 21.45 & 17.2 & 19.65 & 21.9 & 9.4 \\
\hline & 2 & 32.18 & 29.3 & 14.8 & 17.78 & 29.4 & 7.1 \\
\hline & 3 & 34.61 & 30.1 & 20.9 & 21.88 & 33.52 & 9.2 \\
\hline \multirow{3}{*}{$\begin{array}{c}\text { D-5.1-B } \\
\left(2000 \mathrm{~mm}^{2}\right)\end{array}$} & 1 & NA & NA & 4.3 & NA & NA & 3.3 \\
\hline & 2 & 24.63 & 14.68 & 5.1 & 14.84 & 17.98 & 3.1 \\
\hline & 3 & 31.85 & 22.33 & 5.9 & 19.49 & 19.93 & 3.5 \\
\hline \multirow{3}{*}{$\begin{array}{c}\text { D-5.1-C } \\
\left(3000 \mathrm{~mm}^{2}\right)\end{array}$} & 1 & NA & NA & 3.1 & NA & NA & 3.0 \\
\hline & 2 & 20.96 & 15.49 & 4.8 & 9.37 & 12.81 & 1.8 \\
\hline & 3 & 26.81 & 20.81 & 5.8 & 19.4 & 20.94 & 3.6 \\
\hline
\end{tabular}

NA is data not available due to faulty sensors.

Figure 4.10 shows typical displacement shape of tested specimens at different time periods assuming zero displacement at supports. This figure can be used also to show the beam's response type, all specimens responded locally especially during first $15 \mathrm{~ms}$. Beams responded in flexure mode in the first impact, while they responded in shear mode in the successive second and third impacts. This observation is consistent with the obtained failure modes (see Section 4.4). 


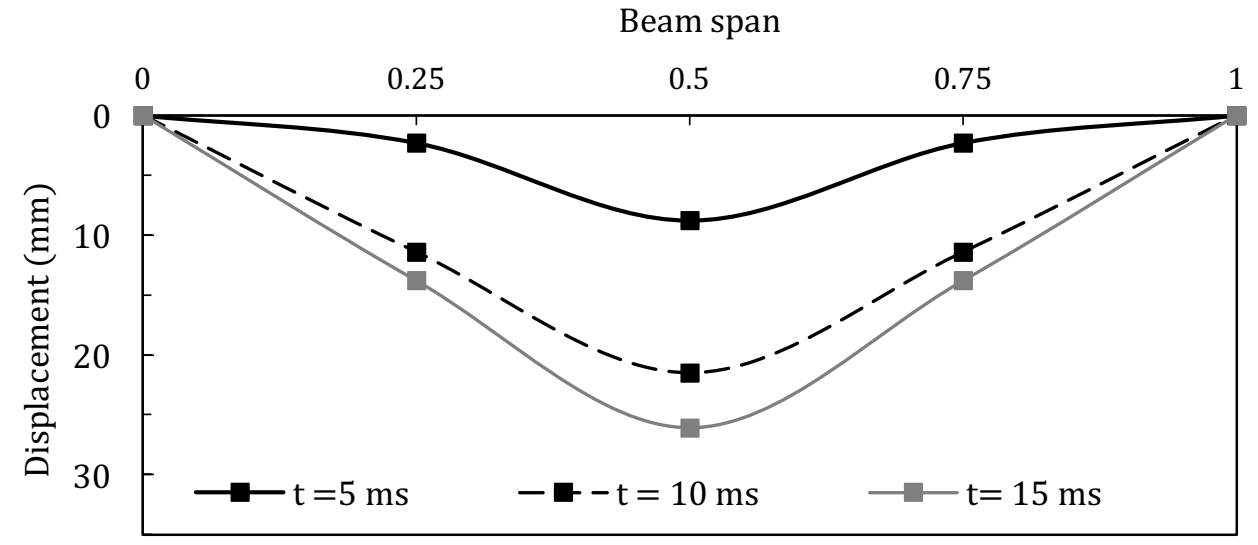

a) First impact test (Flexure mode of deflection)

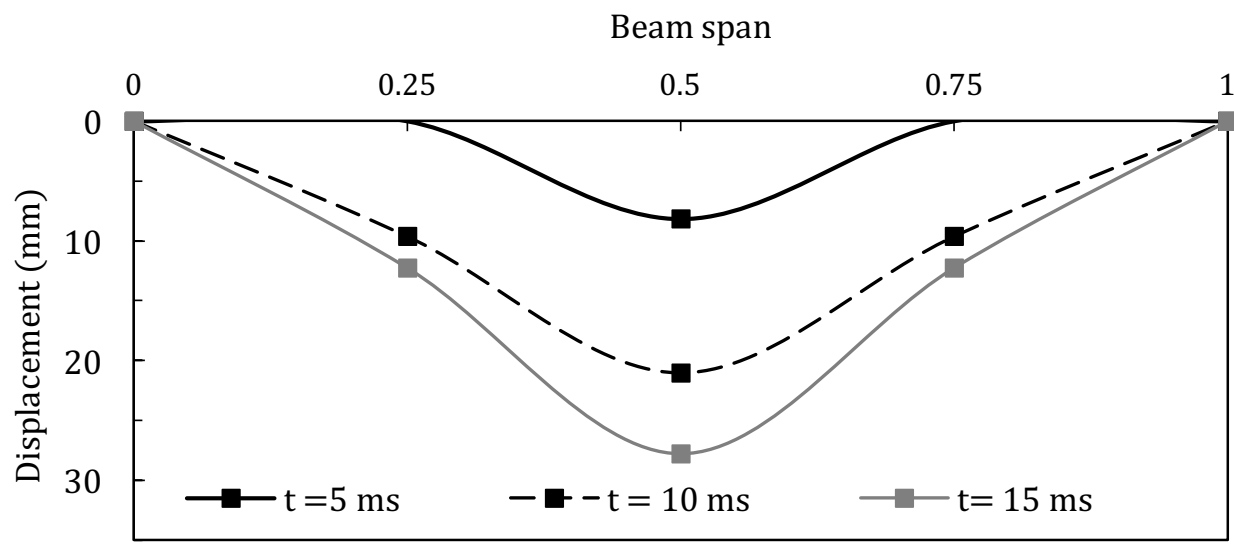

b) Second impact test (Shear mode of deflection)

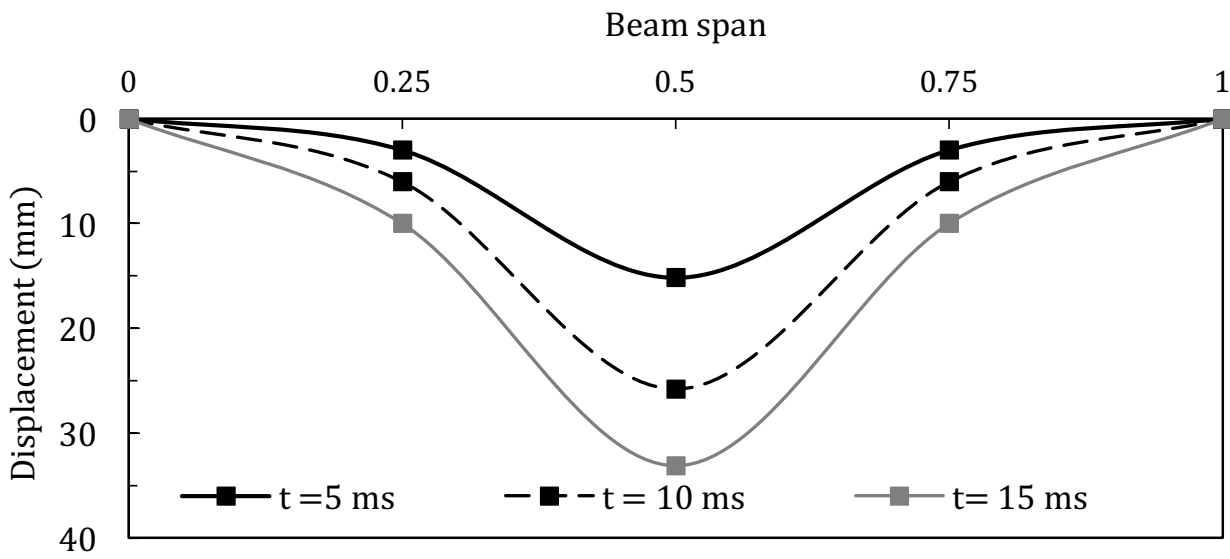

c) Third impact test (Shear mode of deflection)

Figure 4.10 - Deformed shape under successive impact load of D-3.9-A. 


\subsubsection{Steel reinforcement strain response}

This section reports the strain gauge measurements. As mentioned before, two strain gauges are used to monitor the steel reinforcement strain. First strain gauge is attached to longitudinal steel reinforcement at mid span while the other one is attached to vertical stirrups at section of critical shear. Table 4.6 summarizes all the strain gauge measurements. The strain-time histories for all specimens responded typically as shown in Figure 4.11. Under each impact, there is a progressively increasing strain followed by residual plastic strain. It should be pointed out that the time history of second and third impact test represent event measurements and do not include the accumulation of residual values from the previous impact test.

Table 4.6 - Summary of steel reinforcement strain

\begin{tabular}{|c|c|c|c|c|c|c|c|}
\hline \multirow[t]{2}{*}{ Specimen } & \multirow{2}{*}{$\begin{array}{l}\text { Test } \\
\text { No. }\end{array}$} & \multicolumn{3}{|c|}{ Mid span strain } & \multicolumn{3}{|c|}{ Stirrups strain } \\
\hline & & $\begin{array}{l}\text { Peak } \\
(\mathrm{mm})\end{array}$ & $\begin{array}{l}\text { Time } \\
\text { (ms) }\end{array}$ & $\begin{array}{c}\text { Residual } \\
\text { (mm) }\end{array}$ & $\begin{array}{l}\text { Peak } \\
(\mathrm{mm})\end{array}$ & $\begin{array}{l}\text { Time } \\
(\mathrm{ms})\end{array}$ & $\begin{array}{l}\text { Residual } \\
\text { (mm) }\end{array}$ \\
\hline \multirow{3}{*}{$\begin{array}{c}\text { D-3.9-A } \\
\left(900 \mathrm{~mm}^{2}\right)\end{array}$} & 1 & 480 & 150 & 357 & 4606 & 150 & 4048 \\
\hline & 2 & 201 & 120 & 99 & 127 & 110 & 127 \\
\hline & 3 & NA & NA & 105 & 290 & 95 & 180 \\
\hline \multirow{3}{*}{$\begin{array}{c}\text { D-3.9-B } \\
\left(2000 \mathrm{~mm}^{2}\right)\end{array}$} & 1 & 2080 & 8.8 & 734 & 2579 & 4.2 & 381 \\
\hline & 2 & 2699 & 9 & 568 & 2893 & 12 & 514 \\
\hline & 3 & 2322 & 10.2 & 245 & 2731 & 11 & 399 \\
\hline \multirow{3}{*}{$\begin{array}{c}\text { D-3.9-C } \\
\left(3000 \mathrm{~mm}^{2}\right)\end{array}$} & 1 & 181 & 6 & 396 & 3204 & 6.6 & 362 \\
\hline & 2 & 2036 & 7 & 411 & 2438 & 7.2 & 59 \\
\hline & 3 & 1972 & 4.8 & 155 & 1993 & 4.4 & 14 \\
\hline \multirow{3}{*}{$\begin{array}{c}\text { D-5.1-A } \\
\left(900 \mathrm{~mm}^{2}\right)\end{array}$} & 1 & 3856 & 9.2 & 1113 & 93 & 8.6 & 4 \\
\hline & 2 & 2579 & 7.8 & 334 & 58 & 5.2 & 4 \\
\hline & 3 & 3860 & 25.8 & 137 & 26 & 7 & 10 \\
\hline \multirow{3}{*}{$\begin{array}{c}\text { D-5.1-B } \\
\left(2000 \mathrm{~mm}^{2}\right)\end{array}$} & 1 & NA & NA & 121 & NA & NA & 5 \\
\hline & 2 & 340 & 9.8 & 98 & 725 & 2 & 0 \\
\hline & 3 & 290 & 11 & 13 & 607 & 5 & 0 \\
\hline \multirow{3}{*}{$\begin{array}{c}\mathrm{D}-5.1-\mathrm{C} \\
\left(3000 \mathrm{~mm}^{2}\right)\end{array}$} & 1 & 2138 & 18.8 & 635 & 1988 & 16.2 & 308 \\
\hline & 2 & 3660 & 10 & 1407 & 1746 & 4.6 & 63 \\
\hline & 3 & 4193 & 6.6 & 1524 & 1470 & 4.6 & 18 \\
\hline
\end{tabular}

NA is data not available due to faulty sensors. 


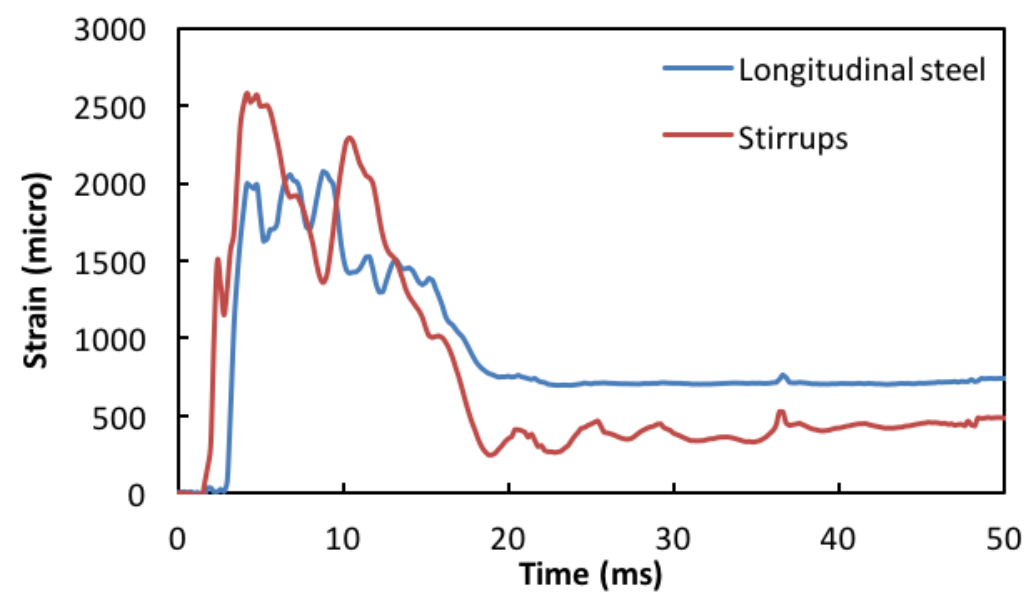

a) First impact test

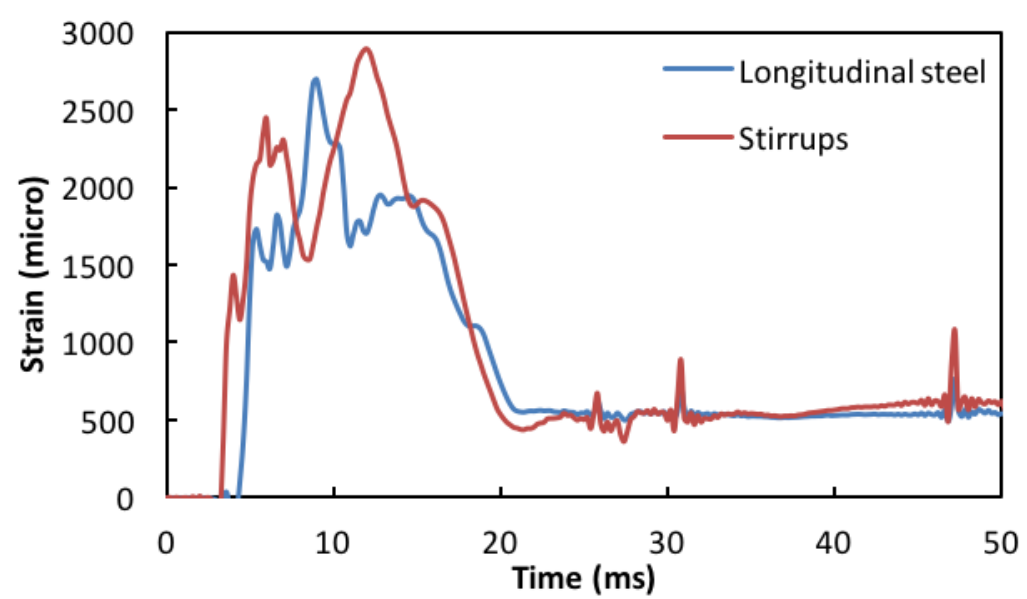

b) Second impact test

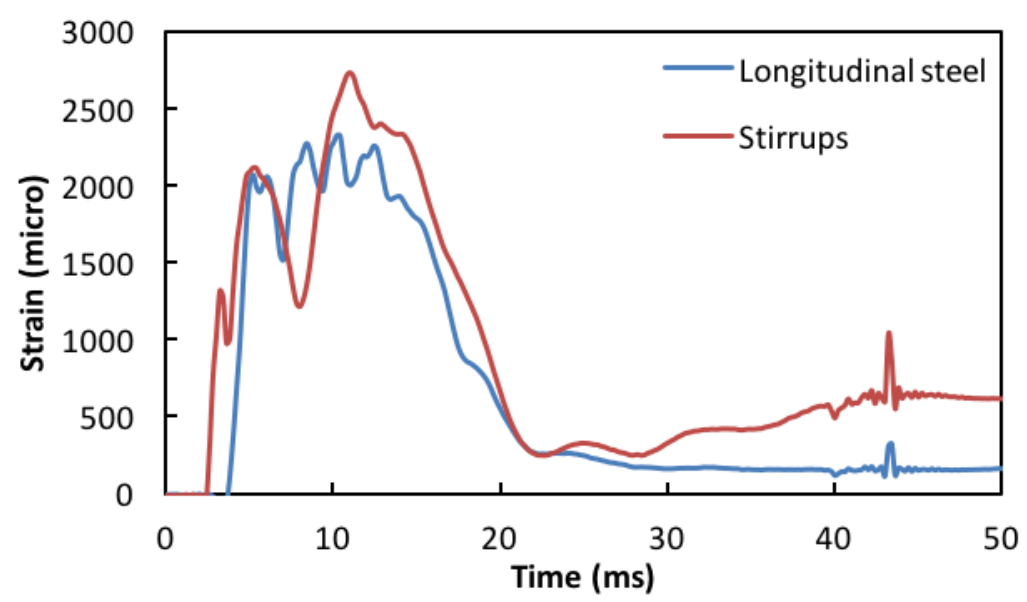

c) Third impact test

Figure 4.11 - Strain time history of D-3.9-B. 


\subsubsection{Damage characteristics and crack patterns}

Based on the observed damage and crack development in the tested specimens, all specimens developed severe diagonal cracks, originating at the impact point and propagating downward with an angle of approximately 45 degrees, forming shear-plugs. In addition, several diagonal cracks parallel to the major shear-plug cracks also developed, along with some vertical flexural cracks at the midspan and at the supports. Flexural cracks also propagated vertically through the height of the beams. The vertical cracks at the midspan started from the bottom surface, whereas the cracks close to the supports started from the top surface. Under the first impact drop, visible shear cracks in drop-weight impact zone are observed. Under subsequent impacts, impacts on the damaged specimens did not change the widths of the cracks located beyond the major diagonal cracks forming the shear-plug; increasing deformations were mostly accommodated by the widening of shear cracks forming the shear-plug. The final crack patterns of tested specimens are shown in Figures 4.12 and 4.13.

The crack patterns and damage level varied between specimens, depending on main steel reinforcement ratio for both studied spans (see Figures 4.11 and 4.12). Beams with higher steel reinforcement ratio suffer more damage and shear cracks are more visible and wider. It should be point out that increasing the span results in more damage and wider shear cracks. 


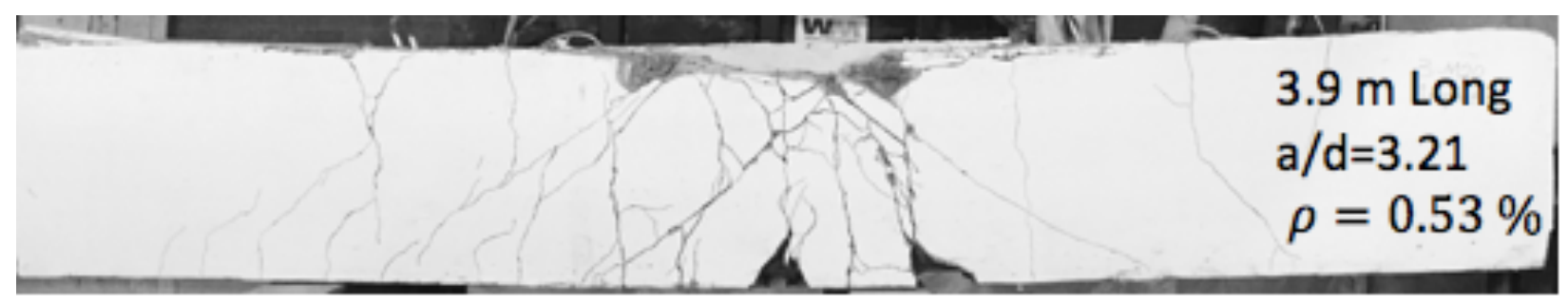

a) D-3.9-A

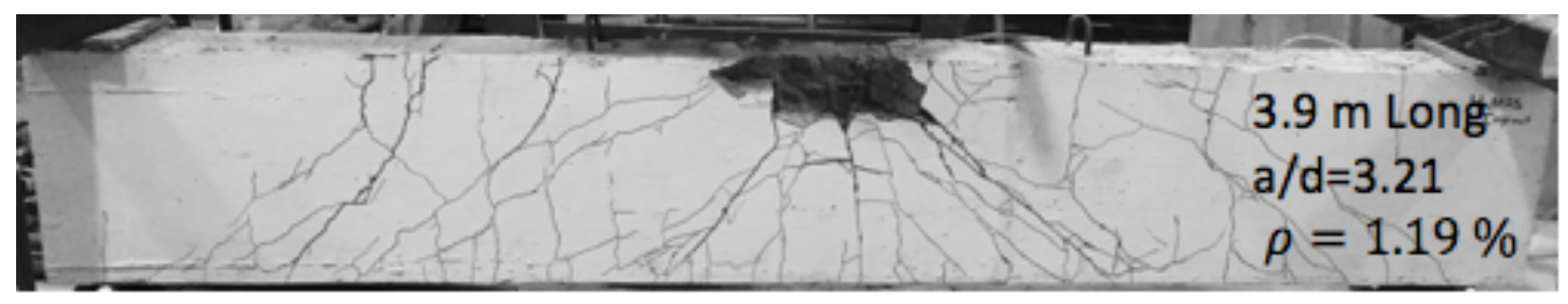

b) D-3.9-B

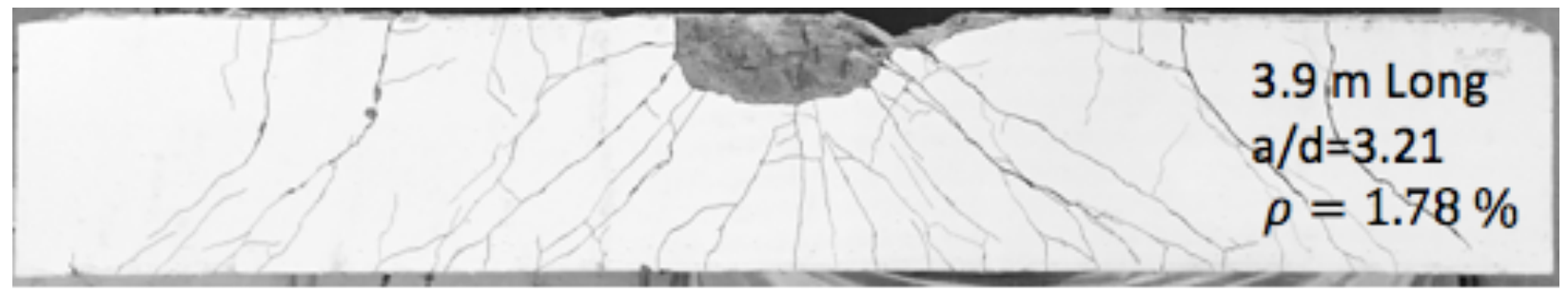

c) D-3.9-C

Figure 4.12 - Final crack patterns of beam specimens with a $3.9 \mathrm{~m}$ span

Table 4.7 summarizes final damage measurements of all the tested specimens. It is obvious from measurements that the increasing main reinforcement plays an important role in controlling the damage. For specimens with identical main bottom steel reinforcement the ejected scabbing concrete weight is decreased by more than $70 \%$ when steel reinforcement is increased. Scabbing mass is also affected by the span. More concrete is ejected from the specimen with the larger span. 


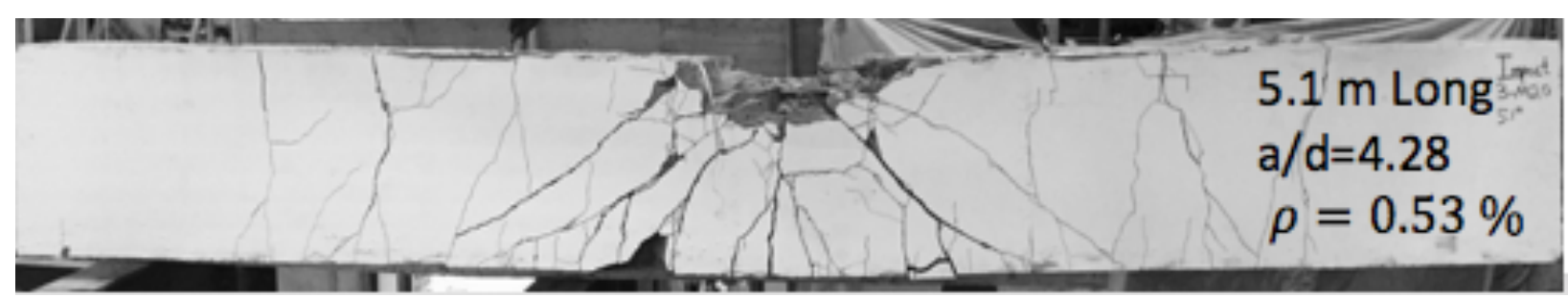

a) D-5.1-A

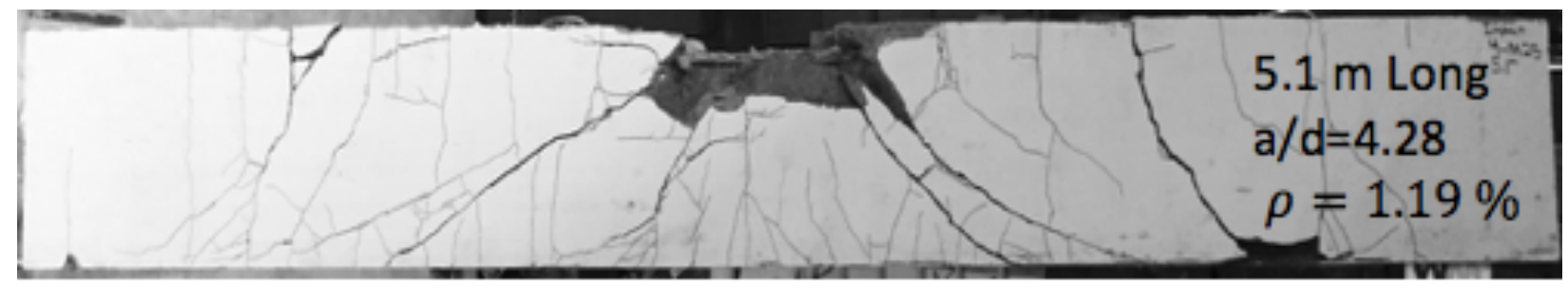

b) D-5.1-B

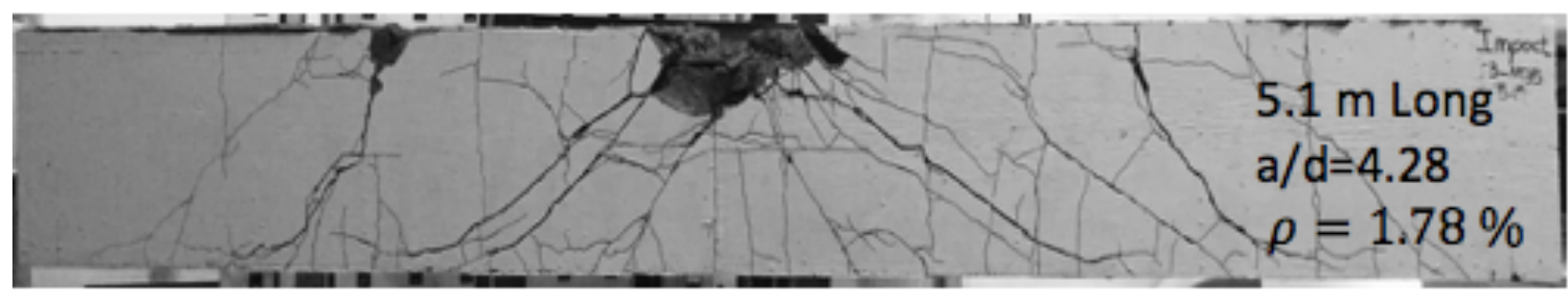

c) D-5.1-C

Figure 4.13 - Final crack patterns of beam specimens with a $5.1 \mathrm{~m}$ span

Table 4.7 - Damage measurements of test specimens

\begin{tabular}{|c|c|c|}
\hline Specimen & $\begin{array}{c}\text { Scabbing } \\
\text { mass } \\
(\mathrm{kg})\end{array}$ & $\begin{array}{c}\text { Residual } \\
\text { displacement } \\
(\mathrm{mm})\end{array}$ \\
\hline D-3.9-A & 34.6 & 45.2 \\
\hline D-3.9-B & 29.2 & 8.5 \\
\hline D-3.9-C & 24.3 & 7.0 \\
\hline D-5.1-A & 40.8 & 52.9 \\
\hline D-5.1-B & 37.9 & 15.3 \\
\hline D-5.1-C & 18.3 & 13.7 \\
\hline
\end{tabular}




\section{Chapter 5}

\section{Conclusion and Recommendation}

\subsection{Conclusions}

An experimental investigation has been conducted on RC beams under impact loading. The experimental program is aimed to develop a performance guideline for the structural behaviour of HSC RC beams under low-velocity impact loads. Two reference concrete beam specimens have been used to determine the static behaviour of the HSC beams.

\subsection{Drop-weight impact testing summary and conclusions}

1. When the impact force is compared to the reaction force, it is evident that peak amplitude of the impact force is greater than that of the reaction force. Most of impact force is used to balance the inertia force or accelerate the beam, while only a small portion of impact force contributes in deforming and fracturing the specimens. There is a time lag between the maximum impact force and the maximum reaction force, which is due to the stress wave propagation traveling from the impact zone to the supports.

2. Under each impact, the midpoint exhibited a progressively increasing peak followed by residual displacements, and the specimen vibrated at the equilibrium position. In case the plastic deformation occurs, the beam vibrates at the new equilibrium position known as permanent displacement offset. 
3. Main reinforcement ratio plays an important role in limiting the peak displacement and residual displacement under impact loading, and increasing the span length decreases the stiffness of the beam resulting in higher displacement peak.

4. Beams with a steel reinforcement ratio ranging from $1.2 \%-1.8 \%$ suffer more damage and shear cracks are more visible and wider compared to beam with a steel reinforcement ratio of $0.5 \%$.

5. Beams with a shear span to effective depth ratio of 4.28 sustained more damage and wider shear cracks in comparison to beams with a shear span to effective depth ratio of 3.21.

6. The same trend is evident for beams under static load with shorter span like beam (S-3.9-B) exhibited higher load carrying and displacement capacity compared to the longer span HSC beam (S-5.1-B) that translates into higher stiffness and absorbed energy.

7. Both beams under static loading with varying span lengths failed in flexural mode with crack formations in the tensile region at mid-span. Mid-span longitudinal steel strain of both beams yielded while the steel stirrup at critical shear locations are intact.

8. Beams designed under static loads with a flexure to shear ratio of 0.5 fail in flexural mode under static loading, while they fail in shear mode under low velocity impact loading.

9. Higher longitudinal reinforcement ratio under impact loading decreases the scabbing mass by more than $70 \%$, while larger span increases the scabbing mass causing more damage. 
10. A static to dynamic load ratio of about 0.5 , and a static to dynamic displacement ratio of about 2 may be utilized for estimating the impact behavior of statically flexure critical high strength reinforced concrete beams.

\subsection{Recommendations for future work}

While the conducted research successfully accomplished the scoped objectives, there are a few recommendations which will be beneficial to future study. The following recommendation are identified during the course of the present research:

1. The use of accelerometer for determining the impact force involved a few challenges as it requires extensive post-processing validation and filtering. The use of special high capacity dynamic (quartz) load cell to measure the impact force is recommended.

2. The effect of shear reinforcement and stirrup spacing on the impact response of HSC beams for both short and long span beams should be fully investigated, since it plays an important role in structural behaviour and stability of RC beams.

3. The effect of compressive longitudinal reinforcement ratio (top reinforcement) should also be looked into for its effect on mass scabbing of HSC beams under impact loading. 


\section{Appendix A: BEAM DESIGN CALCULATION}

All beam design calculations are according to Canadian Concrete Code CSA A23.3 2004.

\section{$\underline{\text { A.1. Static Moment and flexural load capacities }}$}

Concrete compressive strength $\left(f_{c}^{\prime}\right)=80 \mathrm{MPa}$; clear cover $=30 \mathrm{~mm}$;

steel yield stress $\left(f_{y}\right)=400 \mathrm{MPa}$.

\section{a) Beams reinforced with $3-20 \mathrm{M}$}

$A_{s_{\text {min }}}=\frac{0.2 \sqrt{f_{c}^{\prime}} \cdot b_{t} \cdot h}{f_{y}}=\frac{0.2 \sqrt{80}(300 \times 600)}{400}=804.98 \mathrm{~mm}^{2}$

$\mathrm{d}=\mathrm{h}-30 \mathrm{~mm}=570 \mathrm{~mm} ; \mathrm{A}_{\mathrm{s}}=900 \mathrm{~mm}^{2} \rightarrow 3-20 \mathrm{M} ; \mathrm{A}_{\mathrm{s}}^{\prime}=200 \mathrm{~mm}^{2} \rightarrow 2-10 \mathrm{M}$

$\rho=0.53 \%$

$\mathrm{C}_{\mathrm{r}}^{\prime}=\varphi_{\mathrm{s}} \cdot \mathrm{f}_{\mathrm{s}}^{\prime} \cdot \mathrm{A}_{\mathrm{s}}^{\prime}=0.85 \times 400 \times 200=68 \mathrm{kN}$

$T_{r}=\varphi_{\mathrm{s}} \cdot \mathrm{f}_{\mathrm{s}} \cdot \mathrm{A}_{\mathrm{s}}=0.85 \times 400 \times 900=306 \mathrm{kN}$

$\mathrm{a}=\frac{\mathrm{T}_{\mathrm{r}}-\mathrm{C}_{\mathrm{r}}^{\prime}}{\alpha_{1} \varphi_{\mathrm{c}} \mathrm{f}_{\mathrm{c}}^{\prime} \mathrm{b}}=\frac{306-68}{0.73 \times 0.65 \times 80 \times 300}=20.89 \mathrm{~mm}$

$\mathrm{C}_{\mathrm{r}}=\alpha_{1} \cdot \varphi_{\mathrm{c}} \cdot \mathrm{f}_{\mathrm{c}}^{\prime} \cdot \mathrm{a} \cdot \mathrm{b}=0.73 \times 0.65 \times 80 \times 20.89 \times 300=238 \mathrm{kN}$

$M_{r}=C_{r}^{\prime}\left(d-d^{\prime}\right)+C_{r}\left(d-\frac{a}{2}\right)=68(560-30)+238(560-10.4)=166.8 k N . m$

\section{b) Beams reinforced with 4-25M}

$A_{s_{\text {min }}}=\frac{0.2 \sqrt{f_{c}^{\prime}} \cdot b_{t} \cdot h}{f_{y}}=\frac{0.2 \sqrt{80}(300 \times 600)}{400}=804.98 \mathrm{~mm}^{2}$

$\mathrm{d}=\mathrm{h}-30 \mathrm{~mm}=570 \mathrm{~mm} ; \mathrm{A}_{\mathrm{s}}=2000 \mathrm{~mm}^{2} \rightarrow 4-25 \mathrm{M} ; \mathrm{A}_{\mathrm{s}}^{\prime}=200 \mathrm{~mm}^{2} \rightarrow 2-10 \mathrm{M}$

$\rho=1.19 \%$

$\mathrm{C}_{\mathrm{r}}^{\prime}=\varphi_{\mathrm{s}} \cdot \mathrm{f}_{\mathrm{s}}^{\prime} \cdot \mathrm{A}_{\mathrm{s}}^{\prime}=0.85 \times 400 \times 200=68 \mathrm{kN}$ 


$$
\begin{aligned}
& T_{r}=\varphi_{\mathrm{s}} \cdot \mathrm{f}_{\mathrm{s}} \cdot \mathrm{A}_{\mathrm{s}}=0.85 \times 400 \times 2000=680 \mathrm{kN} \\
& \mathrm{a}=\frac{\mathrm{T}_{\mathrm{r}}-\mathrm{C}_{\mathrm{r}}^{\prime}}{\alpha_{1} \varphi_{\mathrm{c}} \mathrm{f}_{\mathrm{c}}^{\prime} \mathrm{b}}=\frac{680-68}{0.73 \times 0.65 \times 80 \times 300}=53.74 \mathrm{~mm} \\
& \mathrm{C}_{\mathrm{r}}=\alpha_{1} \cdot \varphi_{\mathrm{c}} \cdot \mathrm{f}_{\mathrm{c}}^{\prime} \cdot \mathrm{a} \cdot \mathrm{b}=0.73 \times 0.65 \times 80 \times 53.74 \times 300=612 \mathrm{kN} \\
& \mathrm{M}_{\mathrm{r}}=\mathrm{C}_{\mathrm{r}}^{\prime}\left(\mathrm{d}-\mathrm{d}^{\prime}\right)+\mathrm{C}_{\mathrm{r}}\left(\mathrm{d}-\frac{\mathrm{a}}{2}\right)=68(560-30)+680(560-26.87)=362.315 \mathrm{kN} \cdot \mathrm{m}
\end{aligned}
$$

\section{c) Beams reinforced with 3-35M}

$$
\begin{aligned}
& A_{s_{\min }}=\frac{0.2 \sqrt{f_{c}^{\prime}} \cdot b_{t} \cdot h}{f_{y}}=\frac{0.2 \sqrt{80}(300 \times 600)}{400}=804.98 \mathrm{~mm}^{2} \\
& \mathrm{~d}=\mathrm{h}-30 \mathrm{~mm}=570 \mathrm{~mm} ; \mathrm{A}_{\mathrm{s}}=3000 \mathrm{~mm}^{2} \rightarrow 3-35 \mathrm{M} ; \mathrm{A}_{\mathrm{s}}^{\prime}=200 \mathrm{~mm}^{2} \rightarrow 2-10 \mathrm{M} \\
& \rho=1.78 \% \\
& \mathrm{C}_{\mathrm{r}}^{\prime}=\varphi_{\mathrm{s}} \cdot \mathrm{f}_{\mathrm{s}}^{\prime} \cdot \mathrm{A}_{\mathrm{s}}^{\prime}=0.85 \times 400 \times 200=68 \mathrm{kN} \\
& T_{r}=\varphi_{\mathrm{s}} \cdot \mathrm{f}_{\mathrm{s}} \cdot \mathrm{A}_{\mathrm{s}}=0.85 \times 400 \times 3000=1020 \mathrm{kN} \\
& \mathrm{a}=\frac{\mathrm{T}_{\mathrm{r}}-\mathrm{C}_{\mathrm{r}}^{\prime}}{\alpha_{1} \varphi_{\mathrm{c}} \mathrm{f}_{\mathrm{c}}^{\prime} \mathrm{b}}=\frac{1020-68}{0.73 \times 0.65 \times 80 \times 300}=83.59 \mathrm{~mm} \\
& \mathrm{C}_{\mathrm{r}}=\alpha_{1} \cdot \varphi_{\mathrm{c}} \cdot \mathrm{f}_{\mathrm{c}}^{\prime} \cdot \mathrm{a} \cdot \mathrm{b}=0.73 \times 0.65 \times 80 \times 83.59 \times 300=952 \mathrm{kN} \\
& M_{r}=C_{r}^{\prime}\left(d-d^{\prime}\right)+C_{r}\left(d-\frac{a}{2}\right)=68(560-30)+952(560-41.79)=529.37 k N . m
\end{aligned}
$$

\section{A.2. Shear load capacities}

$$
\begin{aligned}
& \mathrm{d}_{\mathrm{v}}=0.9 \mathrm{~d}=504 \mathrm{~mm} ; \beta=0.18 ; \mathrm{A}_{\mathrm{v}}=200 \mathrm{~mm}^{2} ; S=300 \mathrm{~mm} \\
& \mathrm{~V}_{\mathrm{s}}=\frac{\varphi_{\mathrm{s}} \mathrm{A}_{\mathrm{v}} \mathrm{f}_{\mathrm{y}} \operatorname{Cot} \theta}{\mathrm{S}}=\frac{0.85 \times 200 \times 400 \times 504 \times 1.43}{300}=163 . \mathrm{kN} \\
& \mathrm{V}_{\mathrm{c}}=\varphi_{\mathrm{c}} \lambda \beta \sqrt[3]{\mathrm{f}_{\mathrm{c}}} \mathrm{b}_{\mathrm{w}} \mathrm{d}_{\mathrm{v}}=0.65 \times 1 \times 0.18 \times \sqrt[3]{80} \times 300 \times 504=76.22 \mathrm{kN} \\
& \mathrm{V}_{\mathrm{r}}=\mathrm{V}_{\mathrm{c}}+\mathrm{V}_{\mathrm{s}}=239.58 \mathrm{kN}
\end{aligned}
$$




\section{$\underline{\text { A.3. Flexural load carrying capacities }}$}

$\mathrm{M}_{\mathrm{r}}=\frac{\mathrm{PL}}{4} ; \mathrm{P}_{\mathrm{us}}=\frac{4 \cdot \mathrm{M}_{\mathrm{r}}}{\mathrm{L}}$

\section{a) Beams reinforced with $3-20 \mathrm{M}$}

$\mathrm{M}_{\mathrm{r}}=166.8 \mathrm{kN} \cdot \mathrm{m}$

3.9-A Beam: $\quad P_{u s}=\frac{4 . \mathrm{M}_{\mathrm{r}}}{\mathrm{L}}=\frac{4(166.8 \mathrm{kN})}{3.6 \mathrm{~m}}=185.33 \mathrm{kN}$

5.1-A Beam: $\mathrm{P}_{\mathrm{us}}=\frac{4 . \mathrm{M}_{\mathrm{r}}}{\mathrm{L}}=\frac{4(166.8 \mathrm{kN})}{4.8 \mathrm{~m}}=139 \mathrm{kN}$

b) Beams reinforced with 4-25M

$\mathrm{M}_{\mathrm{r}}=326.3 \mathrm{kN} . \mathrm{m}$

3.9-B Beam: $\quad P_{u s}=\frac{4 . \mathrm{M}_{\mathrm{r}}}{\mathrm{L}}=\frac{4(326.3 \mathrm{kN})}{3.6 \mathrm{~m}}=402.57 \mathrm{kN}$

5.1-B Beam: $P_{u s}=\frac{4 . M_{\mathrm{r}}}{\mathrm{L}}=\frac{4(326.3 \mathrm{kN})}{4.8 \mathrm{~m}}=301.929 \mathrm{kN}$

c) Beams reinforced with 3-35M

$\mathrm{M}_{\mathrm{r}}=529.37 \mathrm{kN} . \mathrm{m}$

3.9-B Beam: $\quad \mathrm{P}_{\mathrm{us}}=\frac{4 . \mathrm{M}_{\mathrm{r}}}{\mathrm{L}}=\frac{4(529.37 \mathrm{kN})}{3.6 \mathrm{~m}}=588.18 \mathrm{kN}$

5.1-B Beam: $\mathrm{P}_{\mathrm{us}}=\frac{4 . \mathrm{M}_{\mathrm{r}}}{\mathrm{L}}=\frac{4(529.37 \mathrm{kN})}{4.8 \mathrm{~m}}=441.14 \mathrm{kN}$

\section{A.3. Shear load carrying capacities}

$\mathrm{V}_{\mathrm{us}}=2 \cdot \mathrm{V}_{\mathrm{r}}$

$\mathrm{V}_{\mathrm{r}}=\mathrm{V}_{\mathrm{c}}+\mathrm{V}_{\mathrm{s}}=239.58 \mathrm{kN}$

$\mathrm{V}_{\mathrm{us}}=479.16 \mathrm{kN}$ 


\section{References}

[1] Brzev, Svetlana, and John Pao. Reinforced Concrete Design: A Practical Approach. New York: Pearson Custom, 2009. Print.

[2] MacGregor, J. G., and F. M. P. Bartlett. Reinforced Concrete: Mechanics and Design. Scarborough, Ont.: Prentice Hall Canada, 2000. Print.

[3] S V T Janaka Perera, and Hiroshi Mutsuyoshi. "Shear Behavior of Reinforced High-Strength Concrete Beams." ACI Structural Journal110.1 (2013): 43. Web

[4] Cladera, A., and A. R. Marí. "Shear Design Procedure for Reinforced Normal and High-Strength Concrete Beams using Artificial Neural Networks. Part II: Beams with Stirrups." Engineering Structures26.7 (2004): 927-36. Web.

[5] Rashid, M. A., and M. A. Mansur. "Reinforced High-Strength Concrete Beams in Flexure." SJ ACI Structural Journal 102.3 (2005). Web.

[6] Marzouk, H., and Z. W. Chen. "Fracture Energy and Tension Properties of High-Strength Concrete." J. Mater.

Civ. Eng. Journal of Materials in Civil Engineering7.2 (1995): 108-16. Print.

[7] Ross, C. Allen, and L. Javier Malvar. "Review of Strain Rate Effects for Concrete in Tension." ACI Materials Journal MJ 95.6 (1998): 735-39. Print.

[8] Malvar, L. Javier. "Review of Static and Dynamic Properties of Steel Reinforcing Bars." ACI Materials Journal MJ 95.5 (1998): 609-14. Print.

[9] Pajak, Malgorzata. "The Influence of the Strain Rate on the Strength of Concrete Taking into Account the Experimental Techniques." ACEE (2011): 77-88. Print.

[10] Kishi, N., H. Mikami, K.g. Matsuoka, and T. Ando. "Impact Behavior of Shear-failure-type RC Beams without Shear Rebar." International Journal of Impact Engineering 27.9 (2002): 955-68. Print.

[11] Saatci, Selcuk, and Frank J. Vecchio. "Effects of Shear Mechanisms on Impact Behavior of Reinforced Concrete Beams." SJ ACI Structural Journal 106.1 (2009): 78-86. Print.

[12] Bai, Z. Z., and F. T. K. Au. "Flexural Ductility Design of High-strength Concrete Beams." Struct. Design Tall Spec. Build. The Structural Design of Tall and Special Buildings 22.6 (2011): 521-42. Print.

[13] Othman, H., and H. Marzouk. "An Experimental Investigation on the Effect of Steel Reinforcement on Impact Response of Reinforced Concrete Plates."International Journal of Impact Engineering 88 (2016): 12-21. Print. 
[14] Othman, H., and H. Marzouk. "Impact Response of Ultra-High-Performance Reinforced Concrete Plates." ACI Structural Journal 113.6 (2016): 1-10. Print.

[15] Vogel, Hugues M., and Dagmar Svecova. "Evaluation of Elastic Modulus for High-Strength Concrete." ACI Materials Journal 109.3 (2012): 313-22. Print.

[16] Lee, Joo-Ha, and Young-Soo Yoon. "The effects of cementitious materials on the mechanical and durability performance of high-strength concrete." KSCE Journal of Civil Engineering 19.5 (2014): 1396-404. Print.

[17] El-Sayed, Ahmed K., and Ahmed B. Shuraim. "Size effect on shear resistance of high strength concrete deep beams." Materials and Structures 49.5 (2015): 1871-882. Print.

[18] Hughes G and Beeby AW. "Investigation of the effect of impact loading on concrete beam." The Structural Engineer 60B.3 (1982): 45-52. Print.

[19] Kishi N, Nakano O, Matsouka KG and Ando T. "Experimental study on ultimate strength of flexural-failure type RC beams under impact loading.” Transactions of SMiRT 16.1525 (2001): Print.

[20] Fujikake K, Li B and Soeun S "Impact response of reinforced concrete beam and its analytical evaluation." Journal of Structural Engineering 135.8 (2009): 938-950. Print.

[21] Chen Y and May IM “Reinforced concrete members under drop-weight impacts.” Proceedings of the Institution of Civil Engineers - Structures and Buildings 162.1 (2009): 45-56. Print.

[22] Tachibana S, Masuya H and Nakamura S "Performance based design of reinforced concrete beams under impact.” Natural Hazards and Earth System Sciences 10.6 (2010): 1069-1078. Print.

[23] Kishi N and Mikami H "Empirical formulas for designing reinforced concrete beams under impact loading." ACI Structural Journal 109.4 (2012): 509-519. Print.

[24] Adhikary SD, Li B and Fujikake K "Low velocity impact response of reinforced concrete beams: experimental and numerical investigation.” International Journal of Protective Structures 6.1 (2015): 81-111. Print.

[25] CSA A23.3. (Canadian Standards Association) Design of Concrete Structures. Mississauga - Canada: 2004.

[26] CEB-FIP. Concrete structures under impact and impulsive loading. Lausanne, Switzerland: 1988.

[27] Othman H, Marzouk H. An experimental investigation on the effect of steel reinforcement on impact response of reinforced concrete plates. International Journal of Impact Engineering 2016;88:12-21.

doi:10.1016/j.ijimpeng.2015.08.015. 
[28] Othman H, Marzouk H. Numerical investigation of reinforced concrete slabs under impact loading. In: Bastien

J, Rouleau N, Fiset M, Thomassin M, editors. 10th fib International PhD Symposium in Civil Engineering, Québec, Canada,: 2014, p. 263-70.

[29] Murtiadi S, Marzouk H. Behaviour of high-strength concrete plates under impact loading. Magazine of Concrete Research 2001;53:43-50. doi:10.1680/macr.2001.53.1.43.

[30] ACI Committee 544. Measurement of Properties of Fiber Reinforced Concrete. vol. 85. 1988.

[31] MathWorks. MATLAB® program 2015.

[32] Millard S, Molyneaux T, Barnett S, Gao X. Dynamic enhancement of blast-resistant ultra high performance fibre-reinforced concrete under flexural and shear loading. International Journal of Impact Engineering 2010;37:405-13.

[33] Hrynyk TD, Vecchio FJ. Behavior of Steel Fiber-Reinforced Concrete Slabs under Impact Load. ACI Structural Journal 2014;111:1213-24. doi:10.14359/51686923.

[34] Saatci S, Vecchio F. Effects of shear mechanisms on impact behavior of reinforced concrete beams. ACI Structural Journal 2009;106:78-86.

[35] Soleimani SM, Banthia N. A Novel Drop Weight Impact Setup for Testing Reinforced Concrete Beams. Experimental Techniques 2014;38:72-9. doi:10.1111/j.1747-1567.2012.00810.x.

[36] Kurihashi Y, Taguchi F, Kishi N, Mikami H. Experimental study on static and dynamic response of PVA shortfibre mixed RC slab. fib proceedings of 2 nd International Congress, Naples, Italy: 2006.

[37] Murtiadi S, Marzouk H. Behaviour of high-strength concrete plates under impact loading. Magazine of Concrete Research 2001;53:43-50. doi:10.1680/macr.2001.53.1.43.

[38] Zineddin M, Krauthammer T. Dynamic response and behavior of reinforced concrete slabs under impact loading. International Journal of Impact Engineering 2007;34:1517-34. doi:10.1016/j.ijimpeng.2006.10.012.

[39] Chen Y, May IM. Reinforced concrete members under drop-weight impacts. Proceedings of the ICE Structures and Buildings 2009;162:45-56. doi:10.1680/stbu.2009.162.1.45.

[40] Clough R, Penzien J. Dynamics of structures. third edit. Berkeley, USA: Computers \& Structures, Inc.; 2003.

[41] "IL-300." IL-300 - Sensor heads | IL series | KEYENCE Canada. N.p., n.d. Web. 02 May 2017. 